This Author Accepted Manuscript (AAM) is published in:

Acta Materialia, vol. 150, 15 May 2018, p. 295-307

DOI: $10.1016 /$ j.actamat.2018.03.032

\title{
Elastocaloric effect vs fatigue life: Exploring the durability limits of Ni-Ti plates under pre-strain conditions for elastocaloric cooling
}

\author{
Jaka Tušek ${ }^{1, *}$, Andrej Žerovnik ${ }^{1}$, Matjaž Čebron ${ }^{1}$, Miha Brojan ${ }^{1}$, Borut Žužek ${ }^{2}$, Kurt \\ Engelbrecht $^{3}$, Andrea Cadelli ${ }^{4}$ \\ ${ }^{1}$ Faculty of Mechanical Engineering, University of Ljubljana, Aškerčeva 6, 1000 Ljubljana, Slovenia; \\ ${ }^{2}$ Institute of Metals and Technology, Lepi pot 11, 1000 Ljubljana, Slovenia; \\ ${ }^{3}$ Department of Energy Conversion and Storage, Technical University of Denmark, Frederigsborgvej \\ 399, 4000 Roskilde, Denmark; \\ ${ }^{4}$ SAES Getters S.p.A., Viale Italia 77, 20020 Lainate (Milan), Italy \\ *Corresponding author's e-mail address: jaka.tusek@fs.uni-lj.si
}

\begin{abstract}
Structural fatigue is the major obstacle that prevents practical applications of the elastocaloric effect $(\mathrm{eCE})$ in cooling or heat-pumping devices. Here, the eCE and fatigue behaviour of $\mathrm{Ni}$ Ti plates are systematically investigated in order to define the fatigue strain limit and the associated eCE. Initially, the eCE was evaluated by measuring adiabatic temperature changes at different strain amplitudes and different mean strains along the loading and unloading transformation plateaus. By comparing the eCE with and without pre-strain conditions, the advantages of cycling an elastocaloric material at the mean strain around the middle of the transformation plateau were demonstrated. In the second part of this work, we evaluated the fatigue life at the mean strain of $2.25 \%$ at the loading plateau and at the unloading plateau after initial pre-straining up to $6 \%$ and $10 \%$, respectively. It is shown that on polished samples, durable operation of $10^{5}$ cycles can be reached with a strain amplitude of $0.50 \%$ at the loading plateau, which corresponds to adiabatic temperature changes of approximately $5 \mathrm{~K}$. At the unloading plateau (after initial pre-strain of 10\%), durable operation was reached at a strain
\end{abstract}


This Author Accepted Manuscript (AAM) is published in:

Acta Materialia, vol. 150, 15 May 2018, p. 295-307

DOI: $10.1016 /$ j.actamat.2018.03.032

amplitude of $1.00 \%$, corresponding to adiabatic temperature changes of approximately $8 \mathrm{~K}$. The functional fatigue was analysed after the cycling and it is shown that once the sample has been stabilized there is no further degradation of the eCE, even after $10^{5}$ cycles. These results present guidelines for the design and operation of efficient and durable elastocaloric devices in the future.

Keywords: elastocaloric effect; shape memory alloy; Ni-Ti; fatigue; strain 
This Author Accepted Manuscript (AAM) is published in:

Acta Materialia, vol. 150, 15 May 2018, p. 295-307

DOI: $10.1016 /$ j.actamat.2018.03.032

\section{Introduction}

\subsection{Background and motivation}

Elastocaloric cooling based on the elastocaloric effect (eCE) in shape memory alloys (SMA) is emerging as one of the most promising alternatives to the widely used vapourcompression cooling technology [1], which is relatively inefficient and employs gaseous refrigerants with high Global Warming Potential that can leak and harm the environment. SMAs have been studied extensively over the past couple of decades due to their unique properties, such as the shape memory effect and superelasticity, associated with temperatureinduced and stress-induced martensitic transformation, respectively. Nowadays, SMAs are widely applied in many biomedical and other engineering applications [2]. Recently, a significant focus has also been put on the eCE of SMAs, related with the latent heat of the stress-induced martensitic transformation (superelasticity). The eCE can be characterised as a positive temperature change or negative entropy change during the forward martensitic transformation when a superelastic SMA is loaded at its transformation plateau; and as a negative temperature change or positive entropy change during reverse martensitic transformation upon unloading [3]. Generally, all SMAs can be considered as potential elastocaloric materials when they undergo a stress-induced transformation, and their transformation temperatures are below the operating temperature for the desired application. The most commonly used SMA is binary Ni-Ti alloy (Nitinol), which was first reported in 1963 [4] and remains by far the most widely applied SMA due to its superior fatigue behaviour (over other SMAs) and biocompatibility [2]. Due to the prevalence of Ni-Ti alloys over other SMAs, the eCE is thus the most extensively studied in $\mathrm{Ni}-\mathrm{Ti}$ alloys, where adiabatic temperature changes up to $25 \mathrm{~K}$ have been reported in several studies [5-10]. It was shown that doping $\mathrm{Ni}-\mathrm{Ti}$ with $\mathrm{Cu}$ and $\mathrm{Co}$ or $\mathrm{Fe}$ may improve functional and structural fatigue, while retaining relatively high adiabatic temperature changes (up to $10 \mathrm{~K}$ ) $[11,12]$. A comprehensive 
This Author Accepted Manuscript (AAM) is published in:

Acta Materialia, vol. 150, 15 May 2018, p. 295-307

DOI: $10.1016 /$ j.actamat.2018.03.032

evaluation of transformation temperatures and latent heats of transformation of ternary and quaternary Ni-Ti-based alloys was performed by Frenzel et al. [13]. It was further shown that $\mathrm{Ni}-\mathrm{Ti}-\mathrm{Cu}-\mathrm{V}$ alloys exhibit good functional stability, high latent heat and very low hysteresis width and are therefore a very promising candidate for elastocaloric cooling [14]. Recent comprehensive reviews on elastocaloric materials can be found in $[15,16]$.

Theoretical studies based on experimental characterisation of elastocaloric materials show that elastocaloric cooling can be potentially significantly more efficient than vapourcompression technology $[6,12,17-20]$ as well having a lower environmental impact. Recently, the first prototypes demonstrating a high potential of the eCE as a cooling or heat-pumping mechanism have been developed and tested [21-24]. The most promising results to date were obtained using a regenerative elastocaloric cycle based on a porous elastocaloric material composed of a stack of dog-bone shaped $\mathrm{Ni}$-Ti plates working as an active elastocaloric regenerator loaded in tension [24]. In addition to the positive aspects of the reported prototype, such as high temperature span, high heating/cooling power and potentially high efficiency, limited durability with a fatigue life of only up to 6,000 cycles was reported [25]. This is insufficient for any practical application where fatigue life well above ten million cycles is required [5]. The fatigue life can potentially be improved if the elastocaloric regenerator is loaded in compression [23]. It is known that the fatigue life during compression loading can be significantly better compared to tension loading, as cracks and defects in the material have limited potential to grow and propagate [26]. Longer fatigue life is a big advantage of compression loading for elastocaloric cooling, yet on the other hand, tension loading enables applications of thin elastocaloric elements (which would buckle under compression), that allows for efficient and rapid heat transfer between the elastocaloric material and heat sink/heat source, which is crucial for an efficient elastocaloric device. 
This Author Accepted Manuscript (AAM) is published in:

Acta Materialia, vol. 150, 15 May 2018, p. 295-307

DOI: $10.1016 /$ j.actamat.2018.03.032

Since it has been demonstrated that an elastocaloric regenerator loaded in tension can be very efficient with high specific cooling/heating power [24], the aim of this study is to define the maximum applied strain at which long-term, durable operation (above $10^{5}$ cycles) is reached and to evaluate the associated eCE of commercial Ni-Ti plates loaded in tension at the fatigue strain limits. The results present guidelines for the design and operation of efficient and durable elastocaloric devices in the future.

\subsection{Overview of SMA fatigue behaviour from an elastocaloric perspective}

Despite numerous studies of the eCE in the last years, only minor attention has been put on evaluation of structural fatigue of the elastocaloric materials - despite being crucial for practical applications. Most of the studies (with few exceptions as discussed below) concentrated on the eCE at a very low number of cycles (below 1,000). Therefore, there is a lack of systematic analysis of the fatigue strain limits and related eCE for durable operation of elastocaloric materials. However, Chluba et al. $[12,27]$ demonstrated an ultra-low fatigue NiTi-Cu-Co thin film made by sputtering deposition that can withstand 10 million loading cycles in tension with a strain up to $2.50 \%$ and adiabatic temperature changes up to $10 \mathrm{~K}$. This highly encouraging result already meets the demands of practical applications, but the disadvantage is that the applied sputtering deposition technique is still too time-consuming for large-scale production of this material that would be required in practical cooling or heating applications. Engelbrecht et al. [28] compared fatigue life and eCE of Ni-Ti plates with different surface finishes and different stabilization methods loaded in tension. They showed that a better surface finish leads to longer fatigue life (as expected), but even polished samples failed prior to 5,000 cycles when loaded up to $4 \%$. Very recently, fatigue life and eCE of Ni-Ti, Ni-Ti-Cu, Cu-Zn$\mathrm{Al}$ and $\mathrm{Ni}_{2} \mathrm{FeGa}$ alloys during tension and compression loading were studied by $\mathrm{Wu}$ et al. [26]. 
This Author Accepted Manuscript (AAM) is published in:

Acta Materialia, vol. 150, 15 May 2018, p. 295-307

DOI: $10.1016 /$ j.actamat.2018.03.032

They showed that when loaded in compression, all evaluated alloys reached runout $\left(>10^{4}\right.$ cycles), while during tension loading this was the case only for the $\mathrm{Ni}_{2} \mathrm{FeGa}$ alloy.

As the fatigue of SMAs is generally a major challenge for all its applications, it has been widely studied in the recent years. Following the pioneering work of Melton and Mercier [29], there are several state-of-the-art papers that address different crucial aspects of SMA's fatigue behaviour, such as surface finish [30], inclusions [31, 32], pre-strain conditions [33-36], operating conditions (test temperature, frequency, strain-rate) [37-40], heat treatment during cycling (healing) [41], etc. Since the failure in these materials takes place shortly after the crack nucleation, the interest in the current state-of-the-art is mainly to control crack initiation that is usually caused by surface roughness and/or inclusions [42]. Surface finish is an extremely important parameter for greater fatigue life - polishing (electro-polishing or fine mechanical polishing) or etchings are thus highly recommended [28]. Launey et al. [31] demonstrated that a Ni-Ti alloy with a low inclusion rate showed a 5-fold improvement in fatigue resistance (with an impressive $10^{7}$-cycle fatigue strain limit of $2.50 \%$ ) compared with standard grade Ni-Ti. Urbano et al. [32] performed a comprehensive study on the impact of inclusions in Ni-Ti wires on their fatigue life. They showed that, in particular, large inclusions (above $20 \mu \mathrm{m}$ ) of carbide and/or oxide near the surface of the sample, which effectively act as cracks, can drastically reduce the fatigue life. It was further demonstrated that an applied pre-strain may also significantly influence the fatigue life of SMAs. As reported by Tolomeo et al. [33] and Pelton et al. [34], the fatigue life of Ni-Ti can be increased if the sample is loaded with a mean strain around the middle of the transformation plateau and the total applied strain remains within the plateau. It was shown that a fatigue limit of $10^{7}$ cycles can be reached with a strain amplitude of $0.50 \%$ at a mean strain of $3 \%$ for tension loading [34]. On the other hand, Mahtabi and Shamsaei [35] demonstrated detrimental effects of applying tensile pre-strain on the fatigue behaviour of a superelastic Ni-Ti sample, despite findings from other studies [33, 34] showing 
This Author Accepted Manuscript (AAM) is published in:

Acta Materialia, vol. 150, 15 May 2018, p. 295-307

DOI: $10.1016 /$ j.actamat.2018.03.032

benefits. The impact and benefits of pre-strain on structural fatigue of Ni-Ti alloys are therefore not yet fully understood. Furthermore, Ong et al. [36] showed that if a Ni-Ti wire is initially pre-strained up to $11 \%$ and then cycled at the unload plateau, this can increase the fatigue strain limit (at $10^{7}$ cycles) to a strain amplitude of $0.50 \%$ (compared to $0.12 \%$ at pre-strain up to $4 \%$ ). They argued that large pre-straining generates compressive residual stresses around inclusions and reduces the stress state, which delays the crack initiation process. Interestingly, Wagner et al. [41] demonstrated that periodic annealing of the $\mathrm{Ni}$-Ti samples well above the austenitic finish temperature (also called healing) retransforms the residual martensite accumulated during the superelastic cycling back to the austenitic phase and therefore enhances both structural and functional fatigue. This approach can be a promising method to increase the fatigue life of elastocaloric materials and, by retransforming the residual martensite, to improve the eCE during the cycling. Comprehensive reviews on the fatigue life of SMAs can be found in $[42-45]$.

It is important to distinguish between cycling in the elastic region, where the material is always austenitic, and in the plateau, where the martensitic transformation occurs. As demonstrated by Zheng et al. [46, 47], the failure in superelastic Ni-Ti strips always occurs in the part of the sample where the martensitic transformation with Lüders-like bands occurs. They showed that cyclical loading in the transformation region results in a significantly lower fatigue life compared to cyclical loading in the purely elastic (i.e. austenitic) region [46]. It is known from literature $[44,45]$ that for superelastic SMAs a fatigue limit exceeding $10^{7}$ cycles can be reached with strain amplitudes up to $0.75 \%$, but in most cases this relates mostly with the elastic region, where no phase transformation takes place. It must be emphasized that straining the SMA in the elastic region is useless for elastocaloric applications, as it does not generate the eCE, which is only associated with the austenitic-martensitic transformation (if neglecting R-phase transformation [9, 10]). Furthermore, it should be noted that the great 
This Author Accepted Manuscript (AAM) is published in:

Acta Materialia, vol. 150, 15 May 2018, p. 295-307

DOI: 10.1016/j.actamat.2018.03.032

majority of studies that concluded that the strain amplitude limit of $\mathrm{Ni}$-Ti was up to $0.75 \%$ were performed on wire specimens with a rotary-bending test with fully reversed tensioncompression loading (except where pre-strain was applied, e.g. [33, 34]) or with a diamondshaped specimen, where stresses and strains are highly inhomogeneous over the sample [44, 45]. These experiments cannot be directly applied for elastocaloric cooling, where uniaxial tension-tension or compression-compression loading with a homogenous stress/strain distribution is required. As discussed in [45], the major difference between the rotary-bending and uniaxial fatigue testing is the distribution of stress/strain over the sample. In the rotatingbending test, the surface of the specimen experiences the maximum amount of stress/strain, while the stress/strain values are proportionately smaller in the inner layers as also demonstrated theoretically in [48]. On the other hand, in uniaxial tests the entire specimen's cross section experiences the same amount of stress/strain (if neglecting stress/strain gradients due to Lüders-like martensitic bands in austenitic/martensitic interfaces during the transformation in tension loading - see [49-51] for details). Due to the difference in stress/strain distribution across the section, the effects of surface finish quality on fatigue behaviour may be more pronounced in the rotary-bending tests, while in uniaxial tests the impurities and inclusions in the material may govern the fatigue behaviour of the specimen to a greater degree [45].

The aim of this work is to fill the existing gap in the understanding of the durability limits during uniaxial tension loading of elastocaloric Ni-Ti plates by performing comprehensive analysis of the maximum applied strain at which durable operation is reached together with the associated eCE at the fatigue strain limits. Defining the maximum applied strain (and therefore maximum eCE) that allows for durable operation of $\mathrm{Ni}-\mathrm{Ti}$ elastocaloric plates is crucial for practical elastocaloric applications and has not yet been systematically analysed. As the mean 
This Author Accepted Manuscript (AAM) is published in:

Acta Materialia, vol. 150, 15 May 2018, p. 295-307

DOI: $10.1016 /$ j.actamat.2018.03.032

strain corresponding to the middle of the transformation plateau has two very important advantages for elastocaloric cooling ( $i$. potentially improved fatigue life and $i i$. avoiding useless straining of the material prior to the transformation plateau in a purely austenitic phase with no $\mathrm{eCE}$ - as shown in Section 3.3), this work focuses on the fatigue life and the eCE under prestrain conditions.

\section{Methodology}

Initially, the eCE (i.e. the adiabatic temperature changes) of a Ni-Ti plate was measured at different mean strains along the loading and unloading transformation plateaus with different strain amplitudes. Based on the eCE measurements we defined the optimal mean strain and the strain amplitudes that result in sufficient adiabatic temperature changes (at least $5 \mathrm{~K}$ ), interesting for practical applications and thus for further fatigue-life investigations. The fatigue life was evaluated at different strain amplitudes between $0.50 \%$ and $1.25 \%$ (and thus different adiabatic temperature changes), two different surface finishes and different pre-strain conditions (at loading and unloading plateaus). Runout was set at $10^{5}$ cycles. One should note that in most cases (i.e. in rotary-bending tests) the Ni-Ti samples withstanding $10^{5}$ cycles also reach $10^{6}$ or even $10^{7}$ cycles as shown in e.g. [32, 37, 40].

\subsection{Material}

The material under consideration in this work is a Ni-Ti alloy with 49.1 at.\% $\mathrm{Ti}$ in the form of $200 \mu \mathrm{m}$-thick sheets with an austenite finish temperature $\left(A_{f}\right)$ of approximately $270 \mathrm{~K}$. The material was obtained from Memry Corporation (a SAES Group company). Before cutting the sheets into dog-bone-shaped plates (see Fig. 1(a.)) by Electrical Discharge Machining (EDM), the sheets were etched to remove oxide from the surface. The plates were cut such that the strain is applied along the rolling direction, which results in more pronounced superelasticity 
This Author Accepted Manuscript (AAM) is published in:

Acta Materialia, vol. 150, 15 May 2018, p. 295-307

DOI: $10.1016 /$ j.actamat.2018.03.032

(larger transformation plateau) than when cut normally to rolling direction [52]. After cutting, all plates were tumbled (barrel polishing) in a hexagonal drum for 15 hours. Furthermore, the plates (except three of them) were additionally manually polished, starting from fine grit sandpaper and moving to wax compounds and a buffing wheel (using abrasive papers with up to P2500 grit). Polishing was performed in the direction of strain application to avoid any minor scratches in the direction perpendicular to the loading direction. Figures 1(b.) and 1(c.) show the comparison of surface quality at the edge of the sample before and after manual polishing. The roughness was measured using a 3D optical microscope Infinite Focus G4, while the maximum valley depth (shown in Fig. 1(b.) and 1(c.)) was calculated according to the ISO 25178 standard. It is evident that additional polishing removed most of the remaining cracks from the edge of the sample and significantly reduced maximum valley depth.

\subsection{Training (stabilization) and measurements of the adiabatic temperature changes}

The adiabatic temperature changes were measured using a FLIR A655sc infrared camera with absolute accuracy of $\pm 2 \%$ of the reading, equipped with a $24.6 \mathrm{~mm}$ focal length lens and a $640 \times 480$ pixel IR sensor with spatial resolution of $17 \mu \mathrm{m}$. It should be emphasized that the camera provides a noise equivalent differential temperature (NEDT) that is below $30 \mathrm{mK}$. The measurement uncertainty of the temperature difference between individual pixels is therefore much lower than the absolute temperature uncertainty. In order to capture fast temperature changes at high strain-rates, the thermal images were captured with a frame-rate of up to 50 Hz. The sample was coated with a thin layer of flexible paint (Spray Dye+) with an emissivity of 0.95 . The testing was performed on a Zwick/Roell Z50 universal testing machine, using a 5 $\mathrm{kN}$ XForce P load cell with uncertainty of $\pm 0.20 \%$, while the strain was measured with a longstroke Zwick extensometer with uncertainty of $\pm 0.002 \mathrm{~mm}$. Prior to the measurements, the sample(s) were trained for 125 cycles up to a strain of $6 \%$ with a strain-rate of $0.002 \mathrm{~s}^{-1}$ in order 
This Author Accepted Manuscript (AAM) is published in:

Acta Materialia, vol. 150, 15 May 2018, p. 295-307

DOI: $10.1016 /$ j.actamat.2018.03.032

to stabilize the mechanical behaviour and to assure reproducible results. All tests were performed using position control on the testing machine while the temperature was maintained at $300 \pm 1 \mathrm{~K}$. Once the sample was trained, the adiabatic temperature changes were measured with a strain-rate of $0.06 \mathrm{~s}^{-1}$, which results in well-approached adiabatic conditions for bulk material as shown in [53]. A detailed study on approaching adiabatic conditions in elastocaloric materials is reported in [54]. After each adiabatic loading and unloading, the sample rested at both final positions for $60 \mathrm{~s}$ to stabilize its temperature with the surrounding temperature. At each of the evaluated conditions, three cycles were repeated. Since the temperature changes during the loading and unloading can be highly inhomogeneous over the sample $[3,7,55]$, the adiabatic temperature changes presented in this work are obtained by averaging the temperature values from the thermal images over the entire gauge section of the sample.

\subsection{Fatigue testing}

The fatigue testing was performed on an Instron 8802 universal servo-hydraulic testing machine. The force (stress) was measured with a load cell with a $25 \mathrm{kN}$ capacity and uncertainty of $\pm 0.50 \%$, while strain was calculated using a position displacement (with uncertainty of $\pm 0.01 \mathrm{~mm}$ ). Prior to testing each sample was stabilized as described in Section 2.2. All the samples were cycled with a strain-rate of $0.02 \mathrm{~s}^{-1}$ (with no hold time at final positions) until they failed or reached the runout $\left(10^{5}\right.$ cycles $)$. The fatigue life was evaluated at different strain amplitudes, namely, $0.50 \%, 0.75 \%, 1.00 \%$ and $1.25 \%$, corresponding to different cycling frequencies: $1 \mathrm{~Hz}, 0.67 \mathrm{~Hz}, 0.50 \mathrm{~Hz}$ and $0.40 \mathrm{~Hz}$, respectively. A total of 21 samples were tested for fatigue life.

\section{Results and Discussion}

\subsection{Mechanical training (stabilization)}


This Author Accepted Manuscript (AAM) is published in:

Acta Materialia, vol. 150, 15 May 2018, p. 295-307

DOI: $10.1016 /$ j.actamat.2018.03.032

Figure 2(a.) shows the typical evolution of the superelastic response during training, where functional fatigue (also called mechanical training or stabilization) takes place during initial cycling. After 125 cycles steady conditions with a well reproducible superelastic response were approached. The details of the training effect and the reasons for this phenomenon are explained in various studies, e.g. $[7,56,57]$. In addition to mechanical stabilization, training also results in spatial homogenization of the eCE (adiabatic temperature changes) over the sample as shown and explained in $[7,55]$, which is highly desirable for elastocaloric cooling. Supplementary video 1 and Supplementary video 2 show the temperature changes during loading and unloading at the first five and the last five training cycles, respectively. One can see that in the first few cycles the transformation is very inhomogeneous with highly pronounced Lüders-type transformation bands [49-51], which becomes more homogenously distributed over the sample as it is stabilized.

\subsection{The elastocaloric effect at pre-strain conditions}

Before the adiabatic temperature changes were measured, a quasi-isothermal cycle at a strain-rate of $0.0002 \mathrm{~s}^{-1}$ was performed. Based on this the start, middle and end of the loading and unloading transformation plateaus were defined (see Fig. 2(b.)). The start and the end of the transformation plateau are defined at the strains corresponding to stresses that are $15 \mathrm{MPa}$ lower or higher than the flat section of the plateau (demonstrated with horizontal lines in Fig. 2(b)). The adiabatic temperature changes were measured at three evenly distributed mean strains along the loading as well as the unloading transformation plateaus. Mean strains of $1.75 \%, 2.50 \%, 3.25 \%$ and $1.25 \%, 2.00 \%, 2.75 \%$ were evaluated at the loading and unloading transformation plateau, respectively. The stress-strain curves for each evaluated strain amplitude at different mean strains are shown in Fig. 3. 
This Author Accepted Manuscript (AAM) is published in:

Acta Materialia, vol. 150, 15 May 2018, p. 295-307

DOI: $10.1016 /$ j.actamat.2018.03.032

As seen from Fig. 3 and 4, the adiabatic temperature changes at the strain amplitudes from $0.25 \%$ to $1.00 \%$ were measured at all six evaluated mean strains, while at larger strain amplitudes the adiabatic temperature changes were measured only at the mean strains, which resulted in the minimum strain above $0.25 \%$ and maximum stress below $450 \mathrm{MPa}$. The reasons for that were to prevent buckling (if compressed) and not to exceed the maximum stress reached during the training (450 MPa). The adiabatic temperature changes for all evaluated strain amplitudes as a function of mean strain are shown in Fig. 4. Each value represents an average for three repeated cycles at each condition, with negligible standard deviations - error bars are smaller than circle marks in Fig. 4 and thus are not visible. The results are shown separately for loading where positive adiabatic temperature changes occur (Fig. 4(a.)), and unloading with negative adiabatic temperature changes (Fig. 4(b.)). One can see that adiabatic temperature changes for loading are larger compared to unloading in particular for larger strain amplitudes, which is due to hysteresis energy dissipation. It must be noted that the larger the hysteresis, the larger the temperature irreversibilities [7]. It is also evident from Fig. 4 that as long as the total strain does not exceed the transformation plateau, the adiabatic temperature changes are practically constant for all evaluated mean strains. One can also see that as long as the applied strain remains inside the transformation plateau, the adiabatic temperature changes are independent whether the cycling was performed at the loading or at the unloading plateau. It can be concluded that for all strain amplitudes the largest adiabatic temperature changes occur at the mean strains from around $2.00 \%$ to $2.50 \%$, which corresponds to the middle of loading and unloading transformation plateau.

As the adiabatic temperature changes were measured with thermography, we are able to evaluate also the spatial distribution of the eCE over the sample at different strain amplitudes and different mean strains. Fig. 5 shows the temperature distribution over the sample for different strain amplitudes at mean strain of $2.50 \%$ at the loading plateau, while Fig. 6 shows 
This Author Accepted Manuscript (AAM) is published in:

Acta Materialia, vol. 150, 15 May 2018, p. 295-307

DOI: $10.1016 /$ j.actamat.2018.03.032

the temperature distribution at different mean strains along the loading and unloading plateaus at a strain amplitude of $1.00 \%$. All images in Fig. 5 and 6 have been taken immediately after the loading and unloading processes. It is evident from Fig. 5 and 6 that even in the wellstabilized sample the transformation propagates through a number of rather small Lüders-type transformation bands. One can see from Fig. 5 that the transformation is relatively well homogenized over the sample with the same pattern regardless of the applied strain amplitude. One can also see that the transformation has the same pattern during forward (loading) and reverse (unloading) transformation. On the other hand, when comparing spatial distribution of the $\mathrm{eCE}$ at different mean strains (Fig. 6) it is evident that the transformation pattern over the sample strongly depends on the mean strain and shows the highest homogeneity around the middle of the transformation plateau.

Based on these results, a mean strain of $2.25 \%$ (the average value of the middle of the loading and unloading transformation plateau) and a strain amplitude above $0.50 \%$ were selected for further investigation on fatigue life (see Section 3.4). The selected strain amplitude was chosen as the minimum strain required for generating at least $5 \mathrm{~K}$ of adiabatic temperature change (see Fig. 4), as any smaller adiabatic temperature changes are likely too low for practical applications.

\subsection{The elastocaloric effect at no pre-strain conditions}

To demonstrate the impact and benefits of pre-strain conditions for elastocaloric applications, adiabatic temperature changes were also measured without applying any prestrain. The sample with no pre-strain was tested for strains from $0.50 \%$ to $4.00 \%$ (with a step of $0.50 \%$ ) as shown in Fig. 7. Other testing conditions as well as the training were the same as explained in Section 2.2. 
This Author Accepted Manuscript (AAM) is published in:

Acta Materialia, vol. 150, 15 May 2018, p. 295-307

DOI: $10.1016 /$ j.actamat.2018.03.032

Figure 7(b.) shows and compares adiabatic temperature changes as a function of (total) strain at no pre-strain conditions and at a mean strain of $2.25 \%$ at the loading plateau (error bars show a standard deviation of three repeated cycles at each condition). In the case of the mean strain corresponding to the middle of the transformation plateau, the adiabatic temperature changes are significantly larger when compared to the no pre-strain conditions, especially at smaller strains. The reason for that lays in the loading and unloading in the austenitic phase with no eCE, which occurs at strains below $0.50 \%$ when no pre-strain is applied. This austenitic phase loading that is useless for elastocaloric cooling is avoided when a mean strain around the middle of the transformation plateau is applied. Applying mean strain corresponding to the middle of the transformation plateau results in larger adiabatic temperature changes at the same applied strain compared to the case without applying a prestrain. One can see from Fig. 7(b.) that for the same adiabatic temperature change approximately $0.50 \%$ smaller (total) strain is required in the case of a mean strain of $2.25 \%$ compared to the no pre-strain conditions. However, the temperature irreversibilities (the difference between positive adiabatic temperature change during loading and negative during unloading), in particular at smaller strains, are larger when the pre-strain is applied as the hysteresis that causes energy dissipation is larger when compared to no pre-strain conditions (see Fig. 3 and 7(a.)).

\subsection{Fatigue life}

\subsubsection{Impact of surface quality}

As a first step, the impact of the surface quality on fatigue life was evaluated. Six samples were tested at a strain amplitude of $0.50 \%$ and a mean strain of $2.25 \%$ at the loading plateau (see Fig. 9(a.)). Three of them were tested without being manually polished, while three were manually polished prior to the testing (see Fig. 1). As shown in Fig. 8, the samples that were 
This Author Accepted Manuscript (AAM) is published in:

Acta Materialia, vol. 150, 15 May 2018, p. 295-307

DOI: $10.1016 /$ j.actamat.2018.03.032

not polished failed between 5,000 and 10,000 cycles, while all three polished samples reached runout $\left(>10^{5}\right.$ cycles). It can be concluded that the manual polishing reduced the surface cracks below the critical value at the evaluated strain amplitude, which resulted in significant improvement of the fatigue resistance. Based on the fractography analysis (see Supplementary material) the crack initiation on non-polished, as-received samples occurred in one of the surface cracks at its edge. Therefore, all the samples for further fatigue testing were manually polished in the same way (see Section 2.1).

\subsubsection{Impact of strain amplitude}

The fatigue behaviour was tested also at larger strain amplitudes, namely at $0.75 \%, 1.00 \%$ and $1.25 \%$, as shown in Fig. 9 (again at the mean strain of $2.25 \%$ at the loading plateau). Three, four and two samples were tested at the strain amplitudes of $0.75 \%, 1.00 \%$ and $1.25 \%$, respectively. It is evident from Fig. 9 that even though all the samples were trained (see Section 2.2) before fatigue testing, there was still some further stabilization process going on in the material as the first cycle is quite significantly different than the steady-state cycle, which occurred before or at the $10,000^{\text {th }}$ cycle approximately (see Fig. 10). The evolution of the hysteresis loop during fatigue cycling is shown in Fig. 10, where one can see that during the first hundreds of cycles the hysteresis area decreases until steady-state conditions are reached. The larger the strain amplitude, the larger the number of cycles required for the steady-state conditions. However, as shown in Fig. 9, the samples cycled with the strain amplitudes from $0.75 \%$ to $1.25 \%$ did not reach the runout and they failed between 10,000 and 30,000 cycles. The larger the strain amplitude, the sooner the sample fails. Fractography analysis (see Supplementary material) was performed on two samples tested with a strain amplitude of $1 \%$. In both cases the crack initiation occurred at the front surface of the sample, or near the surface. 
This Author Accepted Manuscript (AAM) is published in:

Acta Materialia, vol. 150, 15 May 2018, p. 295-307

DOI: 10.1016/j.actamat.2018.03.032

However, no inclusions were detected, so the crack initiation most probably occurred due to voids near the surface or due to surface imperfections (e.g., scratches due to polishing).

\subsubsection{Cycling at the unloading plateau}

Next, we tested fatigue behaviour at the unloading plateau after initial pre-straining up to $6 \%$, again at the mean strain of $2.25 \%$, but this time only at a strain amplitude of $1.00 \%$ (Fig. 11(a.)). Three samples were tested in the same way and, interestingly, one sample reached the runout, while the other two failed at approximately 15,000 cycles. Therefore, it seems that cycling at the unloading plateau after an initial pre-strain of $6 \%$ does not really contribute to the enhancement of the fatigue life as the stresses associated with cycling are in the same range as stresses on the loading plateau for the same strain amplitude (see Fig. 9(a) and 11(a)). Fractography analysis (see Supplementary material) shows that both samples that failed have very similar fracture surfaces as for the case of the two samples cycled at the loading plateau (see Section 3.4.2.), with a crack initiation at (or near) the front surface of the sample.

As shown in [36], the partial stabilization of martensite due to a larger initial pre-strain before cycling at the unloading plateau could significantly increase the fatigue life. Thus, other three samples were pre-strained up to $10 \%$ before cycling at a mean strain of $2.25 \%$ at the unloading plateau. As shown in Fig. 11(b.), after the partial recovery of the martensite at the first cycle, the stresses associated with cycling are lower than in the other cases. All three samples tested in this way reached the runout $\left(>10^{5}\right.$ cycles), confirming the results shown in [36] and enabling the durable operation of elastocaloric Ni-Ti plates also at larger strain amplitudes and therefore larger adiabatic temperature changes.

Figure 8 also shows the trend line and empirical correlation that describes the expected number of cycles at the range of strain amplitudes from $0.75 \%$ to $1.25 \%$ at the mean strain of $2.25 \%$. The trend line is based on all manually polished samples that did not reach the runout 
This Author Accepted Manuscript (AAM) is published in:

Acta Materialia, vol. 150, 15 May 2018, p. 295-307

DOI: $10.1016 /$ j.actamat.2018.03.032

tested both at the loading and unloading plateau. Interestingly, as evident from Fig. 8, if the sample (regardless of the cycling conditions) withstands 30,000 cycles, it also reaches the runout ( $10^{5}$ cycles), however, more tests are needed to confirm this.

\subsection{Functional fatigue of the elastocaloric effect after the cycling}

For the evaluation of the functional fatigue, which is crucial for long-term operation of elastocaloric materials, the adiabatic temperature changes were measured also after the cycling. For the samples that reached the runout, the adiabatic temperature changes shown in Fig. 12 were measured after the $100,000^{\text {th }}$ cycle, while for the samples that failed the measurements were performed at around the $10,000^{\text {th }}$ cycle where, according to Fig. 10, full steady-state conditions are reached. It is evident from Fig. 12 that when comparing the adiabatic temperature changes before and after the cycling there is practically no, or very little, degradation of the eCE even after $10^{5}$ cycles. It should be noted that the adiabatic temperature changes shown in Fig. 12 were not measured on a single sample, which might cause some differences in the results. It is not to be expected that all samples have identical mechanical and thermal responses. The adiabatic temperature changes before the cycling were measured on the sample that was not further tested for the fatigue life, while adiabatic temperature changes after cycling were measured on different samples for each evaluated conditions.

It is further evident that in particular for the sample that was initially pre-strained up to $10 \%$ and then cycled at the unloading plateau, the adiabatic temperature changes are smaller compared to other samples tested at a strain amplitude of $1.00 \%$. This large pre-strain caused an additional amount of locked-in martensite in the material (which according to [36] contributes to the fatigue life enhancement) that did not transform and contribute to the eCE during the cycling, which reduces the adiabatic temperature changes. Although the samples that are initially pre-strained to $10 \%$ can tolerate a larger strain amplitude than those with a 
This Author Accepted Manuscript (AAM) is published in:

Acta Materialia, vol. 150, 15 May 2018, p. 295-307

DOI: $10.1016 /$ j.actamat.2018.03.032

lower pre-strain, their adiabatic temperature change is lower at a given strain amplitude. However, the adiabatic temperature change at the highest strain where the samples could reach runout is higher for the $10 \%$ pre-strained samples, proving this to be a promising technique for preparing durable Ni-Ti plates for elastocaloric cooling as well as other SMA's applications.

\section{Conclusions}

The eCE and the fatigue behaviour of Ni-Ti plates were investigated under different prestrain conditions. Initially, with the aim was to demonstrate the beneficial effects of cycling the elastocaloric material around the mean strain that corresponds to the middle of the transformation plateau, the adiabatic temperature changes as a function of the applied strain with and without a pre-strain were compared (Fig. 7). It is shown that for all applied strains the adiabatic temperature changes are significantly larger when the sample is cycled around the middle of the transformation plateau, as in this case the loading and unloading in the purely austenitic phase where there is no eCE is avoided. This is an important advantage for elastocaloric cooling.

In the second part of this work, the fatigue behaviour of $\mathrm{Ni}$-Ti plates at a mean strain of $2.25 \%$ at the loading and unloading plateaus was evaluated for different strain amplitudes. First, the importance of surface quality was demonstrated at a strain amplitude of $0.50 \%$, which corresponds to adiabatic temperature changes of approximately $5 \mathrm{~K}$. At these conditions all three manually polished samples reached runout $\left(10^{5}\right.$ cycles $)$, while as-received samples failed much earlier as expected due to poorer surface quality $[28,30]$. Then, the strain amplitudes were increased up to $1.25 \%$ at the same pre-strain conditions at the loading plateau (for polished samples only) and the samples failed between 10,000 and 30,000 cycles (see Fig. 8). The fatigue-life of polished samples was also evaluated at the unloading plateau (again at the mean strain of $2.25 \%$ ) with a strain amplitude of $1.00 \%$. When the mean strain was reached 
This Author Accepted Manuscript (AAM) is published in:

Acta Materialia, vol. 150, 15 May 2018, p. 295-307

DOI: $10.1016 /$ j.actamat.2018.03.032

after an initial pre-strain of $10 \%$ all three evaluated samples reached the runout, with adiabatic temperature changes of approximately $8 \mathrm{~K}$. Therefore, it was demonstrated that a large initial pre-strain (up to 10\%) and cycling at mean strain around the middle of the unloading transformation plateau is a promising technique to increase the fatigue strain limit and the associated eCE for a long-term operation. However, in the future, a more comprehensive, systematic analysis of fatigue behaviour and related eCE, also at different initial pre-strains and larger strain amplitudes, is required to confirm these results and to demonstrate the fatigue strain limits and maximum eCE using this pre-straining technique for practical (durable) elastocaloric and other superelastic applications.

In the last part of this work, functional fatigue of the Ni-Ti plates after cyclical loading was evaluated (Fig. 12), and it is shown that there is practically no or very little degradation of the eCE even after $10^{5}$ cycles, which is very important for practical applications.

Based on the most comprehensive evaluation of fatigue behaviour of elastocaloric materials to date (regarding the number of tested samples as well as the number of cycles at runout), the results of this work, for the first time, show that it is possible to achieve a relatively large eCE (adiabatic temperature changes of approximately $8 \mathrm{~K}$ ) in the high-cycle fatigue regime [58] of $\mathrm{Ni}$-Ti plates loaded in tension. An adiabatic temperature change of $8 \mathrm{~K}$ is the largest reported adiabatic temperature change at durable operation of $\mathrm{Ni}$-Ti alloys and is significantly larger than adiabatic temperature changes of the known electrocaloric and magnetocaloric materials at realistic conditions for practical solid-state cooling applications. For example, magnetocaloric materials at realistic magnetic fields for practical applications (up to $1.5 \mathrm{~T}$ ) exhibit adiabatic temperature changes up to $5 \mathrm{~K}$ [59], while multi-layered electrocaloric ceramic materials exhibit adiabatic temperature changes up to $1.5 \mathrm{~K}$ in conditions that allow for durable operation (> $10^{6}$ cycles) [60]. The results of this work therefore present an important 
This Author Accepted Manuscript (AAM) is published in:

Acta Materialia, vol. 150, 15 May 2018, p. 295-307

DOI: $10.1016 /$ j.actamat.2018.03.032

guideline for the design and operation of efficient and powerful elastocaloric regenerators as the key element of elastocaloric cooling and heat-pumping devices.

\section{Acknowledgements}

The authors are grateful to Memry Corporation for providing the Ni-Ti samples. The authors would also like to thank Prof. Iztok Golobič (Laboratory for Thermal Technology, Faculty of Mechanical Engineering, University of Ljubljana) for kindly lending the IR camera (FLIR A655sc). Jaka Tušek would also like to acknowledge the financial support provided by the Slovenian Research Agency (Project No. Z2-7219).

\section{Appendix A. Supplementary data}

Supplementary data related to this article can be found at: Supplementary material, Supplementary video 1 and Supplementary video 2.

\section{References}

[1] W. Goetzler,R. Zogg, J. Young, C. Johnson, Energy savings potential and R\&D opportunities for non-vapor-compression HVAC technologies, Navigant Consulting, Inc., prepared for U.S. Department of Energy (2014).

[2] J.M. Jani, M. Leary, A. Subic, M.A. Gibson, A review of shape memory alloy research, applications and opportunities, Mater. Des. 56 (2014) 1078-1113.

[3] J. Tušek, K. Engelbrecht, L. Mañosa, E. Vives, N. Pryds, Understanding the thermodynamic properties of the elastocaloric effect through experimentation and modelling, Shape Mem. Superelast. 2 (2016) 317-329. 
This Author Accepted Manuscript (AAM) is published in:

Acta Materialia, vol. 150, 15 May 2018, p. 295-307

DOI: $10.1016 /$ j.actamat.2018.03.032

[4] W.J. Buehler, J.W. Gilfrich, R.C. Wiley, Effects of low-temperature phase changes on the mechanical properties of alloys near composition TiNi, J. Appl. Phys. 34 (1963) 1475 1477.

[5] J. Cui, Y. Wu, J. Muehlbauer, Y. Hwang, R. Radermacher, S. Fackler, M. Wuttig, I. Takeuchi, Demonstration of high efficiency elastocaloric cooling with large $\Delta \mathrm{T}$ using NiTi wires, Appl. Phys. Lett. 101 (2012) 073904.

[6] H. Ossmer, F. Lambrecht, M. Gultig, C. Chluba, E. Quandt, M. Kohl, Evolution of temperature profiles in TiNi films for elastocaloric cooling, Acta Mater. 81 (2014) 9-20.

[7] J. Tušek, K. Engelbrecht, L.P. Mikkelsen, N. Pryds, Elastocaloric effect of Ni-Ti wire for application in a cooling device, J. Appl. Phys. 117 (2015) 124901

[8] G.J. Pataky, E. Ertekin, H. Sehitoglu, Elastocaloric cooling potential of $\mathrm{NiTi}, \mathrm{Ni}_{2} \mathrm{FeGa}$, and CoNiAl, Acta Mater. 96 (2015) 420-427.

[9] D. Soto-Parra, E. Vives, L. Mañosa, J. A. Matutes-Aquino, H. Flores-Zúñiga, A. Planes, Elastocaloric effect in Ti-Ni shape-memory wires associated with the B2 $\leftrightarrow$ B19' and B2 ↔ R structural transitions, Appl. Phys. Lett. 108 (2016) 071902 .

[10] X. Liang, F. Xiao, M. Jin, X. Jin, T. Fukuda, T. Kakeshita, Elastocaloric effect induced by the rubber-like behavior of nanocrystalline wires of a Ti-50.8Ni (at.\%) alloy, Scripta Mater. 134 (2017) 42-46.

[11] C. Bechtold, C. Chluba, R. Lima de Miranda, E. Quandt, High cyclic stability of the elastocaloric effect in sputtered TiNiCu shape memory films, Appl Phys Lett 101 (2012) 091903.

[12] C. Chluba, H. Ossmer, C. Zamponi, M. Kohl, E. Quandt, Ultra-low fatigue quaternary TiNi-based films for elastocaloric cooling, Shape Mem. Superelast. 2 (2016) 95-103. 
This Author Accepted Manuscript (AAM) is published in:

Acta Materialia, vol. 150, 15 May 2018, p. 295-307

DOI: $10.1016 /$ j.actamat.2018.03.032

[13] J. Frenzel, A. Wieczorek, I. Opahle, B. Maaß, R. Drautz, G. Eggeler, On the effect of alloy composition on martensite start temperatures and latent heats in $\mathrm{Ni}$-Ti-based shape memory alloys, Acta Mater. 90 (2015) 213-231.

[14] A. Wieczorek, J. Frenzel, M. Schmidt, B. Maßß, S. Seelecke, A. Schütze, G. Eggeler, Optimizing Ni-Ti-based shape memory alloys for ferroic cooling, Funct. Mater. Lett. 10 (2017) 1740001.

[15] L. Mañosa, A. Planes, Materials with giant mechanocaloric effects: cooling by strength, Adv. Mater. 29 (2107) 1603607.

[16] H. Sehitoglu, Y.Wu, E. Ertekin, Elastocaloric effect in the extreme, Scripta Mater (2017) In press.

[17] S. Qian, J. Ling, Y. Hwang, R. Radermacher, I. Takeuchi, Thermodynamics cycle analysis and numerical modeling of thermoelastic cooling systems, Int. J. Refrigeration 56 (2015) 65-80.

[18] S. Qian, A. Alabdulkarem, J. Ling, J. Muehlbauer, Y. Hwang, R. Radermacher, I. Takeuchi, Performance enhancement of a compressive thermoelastic cooling system using multi-objective optimization and novel designs, Int. J. Refrigeration 57 (2015) 62-76.

[19] J. Tušek, K. Engelbrecht, R. Millán-Solsona, L. Mañosa, E. Vives, L. P. Mikkelsen, N. Pryds, The elastocaloric effect: a way to cool efficiently, Adv. En. Mater. 5 (2015) 1500361.

[20] D. Luo, Y. Feng, P. Verma, Modeling and analysis of an integrated solid state elastocaloric heat pumping system, Energy 130 (2017) 500-514.

[21] M. Schmidt, A. Schütze S. Seelecke, Scientific test setup for investigation of shape memory alloy based elastocaloric cooling processes, Int. J. Refrigeration 54 (2015) 85-97.

[22] H. Ossmer, F. Wendler, M. Gueltig, F. Lambrecht, S. Miyazaki, M. Kohl, Energyefficient miniature-scale heat pumping based on shape memory alloys, Smart Mater. Struct. 25 (2016) 085037. 
This Author Accepted Manuscript (AAM) is published in:

Acta Materialia, vol. 150, 15 May 2018, p. 295-307

DOI: $10.1016 /$ j.actamat.2018.03.032

[23] S. Qian, Y. Wu, J. Ling, J. Muehlbauer, Y. Hwang, I. Takeuchi, R. Radermacher, Design, development and testing of a compressive thermoelastic cooling system, Proceedings of the 24th IIR International Congress of Refrigeration (2015) 0092.

[24] J. Tušek, K. Engelbrecht, D. Eriksen, S. Dall'Olio, J. Tušek, N. Pryds, A regenerative elastocaloric heat pump, Nat. Energy 1 (2016) 16134.

[25] K. Engelbrecht, J. Tušek, D. Eriksen, T. Lei, C.-Y. Lee, J. Tušek, N. Pryds, A regenerative elastocaloric device: experimental results, J. Phys. D Appl. Phys. 50 (2017) 424006.

[26] Y. Wu, E. Ertekin, H. Sehitoglu, Elastocaloric cooling capacity of shape memory alloys

- Role of deformation temperatures, mechanical cycling, stress hysteresis and inhomogeneity of transformation, Acta Mater. 135 (2017) 158-176.

[27] C. Chluba, W. Ge, R. Lima de Miranda, J. Strobel, L. Kienle, E. Quandt, M. Wuttig, Ultralow-fatigue shape memory alloy films, Science 29 (2015) 1004-1007.

[28] K. Engelbrecht, J. Tušek, S. Sanna, D. Eriksen, O. Mishin, C. Bahl, N. Pryds, Effects of surface finish and mechanical training on Ni-Ti sheets for elastocaloric cooling, APL Mater. 4 (2016) 064110.

[29] K. N. Melton, O. Mercier, Fatigue of NiTi thermoelastic martensites, Acta Metall. 27 (1979) 137-144.

[30] M. M. Patel, R.F. Gordon, An Investigation of Diverse Surface Finishes on Fatigue Properties of Superelastic Nitinol Wire, Proceeding of the International Conference on Shape Memory and Superelastic Technologies (2006).

[31] M. Launey, S.W. Robertson, L. Vien, K. Senthilnathan, P. Chintapalli, A.R. Pelton, Influence of microstructural purity on the bending fatigue behaviour of VAR-melted superelastic Nitinol, J. Mech. Behav. Biomed. Mater. 34 (2014) 181-186. 
This Author Accepted Manuscript (AAM) is published in:

Acta Materialia, vol. 150, 15 May 2018, p. 295-307

DOI: $10.1016 /$ j.actamat.2018.03.032

[32] M.F. Urbano, A. Cadelli, F. Sczerzenie, P. Luccarelli, S. Beretta, A. Coda, Inclusions size-based fatigue life prediction model of NiTi alloy for biomedical applications, Shape Mem. Superelast. 1 (2015) 240-251.

[33] D. Tolomeo, S. Davidson, M. Santinoranont, Cyclic properties of superelastic Nitinol: design implications, Proceeding of the International Conference on Shape Memory and Superelastic Technologies (2000).

[34] A.R. Pelton, X.-Y. Gong, T. Duering, Fatigue testing of diamond-shaped specimens, Proceeding of the International Conference on Shape Memory and Superelastic Technologies (2003).

[35] M.J. Mahtabi, N. Shamsaei, A modified energy-based approach for fatigue life prediction of superelastic NiTi in presence of tensile mean strain and stress, Int. J. Mech. Sci. 117 (2016) 321-333.

[36] I. Ong, L. Vien, D. Madamba, K. Senthilnathan, T. Duerig, A. Shamimi, Effect of PreStrain on Nitinol Fatigue Life, Presentation in the International Conference on Shape Memory and Superelastic Technologies (2015).

[37] S. Miyazaki, K. Mizukoshi, T. Ueki, T. Sakuma, Yinong Liu, Fatigue life of Ti-50 at.\% $\mathrm{Ni}$ and $\mathrm{Ti}-40 \mathrm{Ni}-10 \mathrm{Cu}$ (at.\%) shape memory alloy wires, Mater. Sci. Eng. A 273-275 (1999) $658-663$.

[38] G. Eggeler, E. Hornbogen, A. Yawny, A. Heckmann, M. Wagner, Structural and functional fatigue of NiTi shape memory alloys, Mater. Sci. Eng. A 378 (2004) 24-33.

[39] Y. Zhang, Y. You, Z. Moumni, G. Anlas, J. Zhu, W. Zhang, Experimental and theoretical investigation of the frequency effect on low cycle fatigue of shape memory alloys, Int. J. Plasticity 90 (2017) 1-30. 
This Author Accepted Manuscript (AAM) is published in:

Acta Materialia, vol. 150, 15 May 2018, p. 295-307

DOI: $10.1016 /$ j.actamat.2018.03.032

[40] E. Alarcon, L. Heller, S. Arbab Chirani, P. Šittner, J. Kopeček, L. Saint-Sulpice, S. Calloch, Fatigue performance of superelastic NiTi near stress-induced martensitic transformation, Int. J. Fatigue 95 (2017) 76-89.

[41] M.F.-X. Wagner, N. Nayan, U. Ramamurty, Healing of fatigue damage in NiTi shape memory alloys, J. Phys. D: Appl. Phys. 41 (2008) 185408.

[42] S. W. Robertson, A. R. Pelton, R. O. Ritchie, Mechanical fatigue and fracture of Nitinol, Int. Mater. Rev. 57 (2012) 1-37.

[43] A.R. Pelton, Nitinol fatigue: a review of microstructures and mechanisms, J. Mater. Eng. Perform. 20 (2011) 613-617.

[44] M.J. Mahtabi, N. Shamsaei, M.H. Elahinia, Fatigue of shape memory alloys, In: M.H. Elahinia (Ed.), Shape memory alloy actuators: design, fabrication and experimental evaluation, John Wiley \& Sons, Ltd, 2016.

[45] M.J. Mahtabi, N. Shamsaei, M.R. Mitchell, Fatigue of Nitinol: The state-of-the-art and ongoing challenges, J. Mech. Behav. Biomed. Mater. 50 (2015) 228-254.

[46] L. Zheng, Y. He, Z. Moumni, Lüders-like band front motion and fatigue life of pseudoelastic polycrystalline NiTi shape memory alloy, Scripta Mater. 123 (2016) 46-50

[47] L. Zheng, Y. He, Z. Moumni, Effects of Lüders-like bands on NiTi fatigue behaviors, Int. J. Solids Struct. 83 (2016) 28-44.

[48] M.F.-X. Wagner, G. Eggeler, Stress and strain states in a pseudoelastic wire subjected to bending rotation, Mech. Mater. 38 (2006) 1012-1025.

[49] P. Sedmák, J. Pilch, L. Heller, J. Kopeček, J. Wright, P. Sedlák, M. Frost, P. Šittner, Grain-resolved analysis of localized deformation in nickel-titanium wire under tensile load, Science 353 (2016) 559-562.

[50] J.A. Shaw, S. Kyriakides, On the nucleation and propagation of phase transformation fronts in a NiTi alloy. Acta Mater. 45 (1997) 683-700. 
This Author Accepted Manuscript (AAM) is published in:

Acta Materialia, vol. 150, 15 May 2018, p. 295-307

DOI: $10.1016 /$ j.actamat.2018.03.032

[51] P. Sittner, Y. Liu, V. Novak, On the origin of Lüders-like deformation of NiTi shape memory alloys. J. Mech. Phys. Solids 53 (2005) 1719-1746.

[52] Y. Liu, The superelastic anisotropy in a NiTi shape memory alloy thin sheet. Acta Mater. 95 (2015) 411-427.

[53] M. Schmidt, A. Schütze, S. Seelecke, Elastocaloric cooling processes: The influence of material strain and strain rate on efficiency and temperature span. APL Mater. 4 (2016) 064107. [54] S. Qian, L. Yuan, J. Yu, G. Yan, The mechanism of $\Delta \mathrm{T}$ variation in coupled heat transfer and phase transformation for elastocaloric materials and its application in materials characterization. Appl. Phys. Lett. 111 (2017) 223902.

[55] M. Schmidt, J. Ullrich, A. Wieczorek, J. Frenzel, A. Schütze, G. Eggeler, S. Seelecke, Thermal Stabilization of NiTiCuV Shape Memory Alloys: Observations During Elastocaloric Training. Shape Mem. Superelast. 1 (2015) 132-141.

[56] S. Miyazaki, T. Imai, Y. Igo, K. Otsuka, Effect of cyclic deformation on the pseudoelasticity characteristics of Ti-Ni alloys. Metall. Trans. A 17 (1986) 115-120.

[57] J. Olbricht, A. Yawny, A. M. Condo, F. C. Lovey, G. Eggeler, The influence of temperature on the evolution of functional properties during pseudoelastic cycling of ultra fine grained NiTi Mater. Sci. Eng. A 481-482 (2008) 142-145.

[58] A.R. Pelton, J. Fino-Decker, L.Vien, C.Bonsignore, P.Saffari, M. Launey, M.R.Mitchell, Rotary-bending fatigue characteristics of medical-grade Nitinol wire, J. Mech. Behav. Biomed. Mater. 27 (2013) 19-32.

[59] A. Kitanovski, J. Tušek, U. Tomc, U. Plaznik, M. Ožbolt, A. Poredoš, Magnetocaloric Energy Conversion, Springer International Publishing, Switzerland, 2015.

[60] L. Fulanović, J. Koruza, N. Novak, F. Weyland, B. Malič, V. Bobnar, Fatigue-less electrocaloric effect in relaxor $\mathrm{Pb}\left(\mathrm{Mg}_{1 / 3} \mathrm{Nb}_{2 / 3}\right) \mathrm{O}_{3}$ multilayer elements. J. Eur. Ceram. Soc. 37 (2017) 5105-5108. 
This Author Accepted Manuscript (AAM) is published in:

Acta Materialia, vol. 150, 15 May 2018, p. 295-307

DOI: $10.1016 /$ j.actamat.2018.03.032

\section{Figure captions}

Fig. 1. Dimensions of evaluated samples in $\mathrm{mm}$ (a.) and a comparison of surface quality at the edge of the sample before (b.) and after (c.) manual polishing.

Fig 2. The stabilization of the superelastic response during training cycling (a.). The stabilized isothermal superelastic cycle with marked start, middle and end of the loading and the unloading transformation plateau (b.).

Fig. 3. Stress-strain characteristics for different strain amplitudes at different mean strains along the loading and unloading transformation plateau.

Fig. 4. Positive adiabatic temperature changes during loading (a.) and negative adiabatic temperature changes during unloading (b.) as a function of the mean strain for different strain amplitudes. Closed circles mark the adiabatic temperature changes measured at the loading plateau, while open circles at the unloading plateau.

Fig. 5. Temperature distribution (in ${ }^{\circ} \mathrm{C}$ ) over the sample immediately after the loading and unloading with strain amplitudes from $0.25 \%$ to $2.00 \%$ at mean strain of $2.50 \%$ at the loading plateau.

Fig. 6. Temperature distribution (in ${ }^{\circ} \mathrm{C}$ ) over the sample immediately after loading and unloading with a strain amplitude of $1.00 \%$ at mean strains of $1.75 \%, 2.50 \%, 3.25 \%$ at the loading plateau and $1.25 \%, 2.00 \%, 2.75 \%$ at the unloading plateau, respectively.

Fig. 7. Stress-strain characteristics at no pre-strain conditions (a.). A comparison of adiabatic temperature changes as a function of total strain at no pre-strain conditions and at a mean strain of $2.25 \%$ at the loading plateau (b.).

Fig. 8. Strain-life fatigue data for all evaluated samples.

Fig. 9. Stress-strain characteristics of the first and the last cycles during fatigue testing at different strain amplitudes at the mean strain of $2.25 \%$ at the loading plateau. 
This Author Accepted Manuscript (AAM) is published in:

Acta Materialia, vol. 150, 15 May 2018, p. 295-307

DOI: $10.1016 /$ j.actamat.2018.03.032

Fig. 10. The energy of hysteresis area during fatigue testing as function of cycle number for different strain amplitudes (at the mean strain of $2.25 \%$ at the loading plateau).

Fig. 11. Stress-strain characteristics of the first (two) and the last cycle during fatigue testing at the strain amplitude of $1 \%$ and the mean strain of $2.25 \%$ at the unloading plateau after the initial pre-strain up to $6 \%$ (a.) and $10 \%$ (b.).

Fig. 12. Comparison of adiabatic temperature changes before and after fatigue cycling. 
This Author Accepted Manuscript (AAM) is published in:

Acta Materialia, vol. 150, 15 May 2018, p. 295-307

DOI: 10.1016/j.actamat.2018.03.032

a.
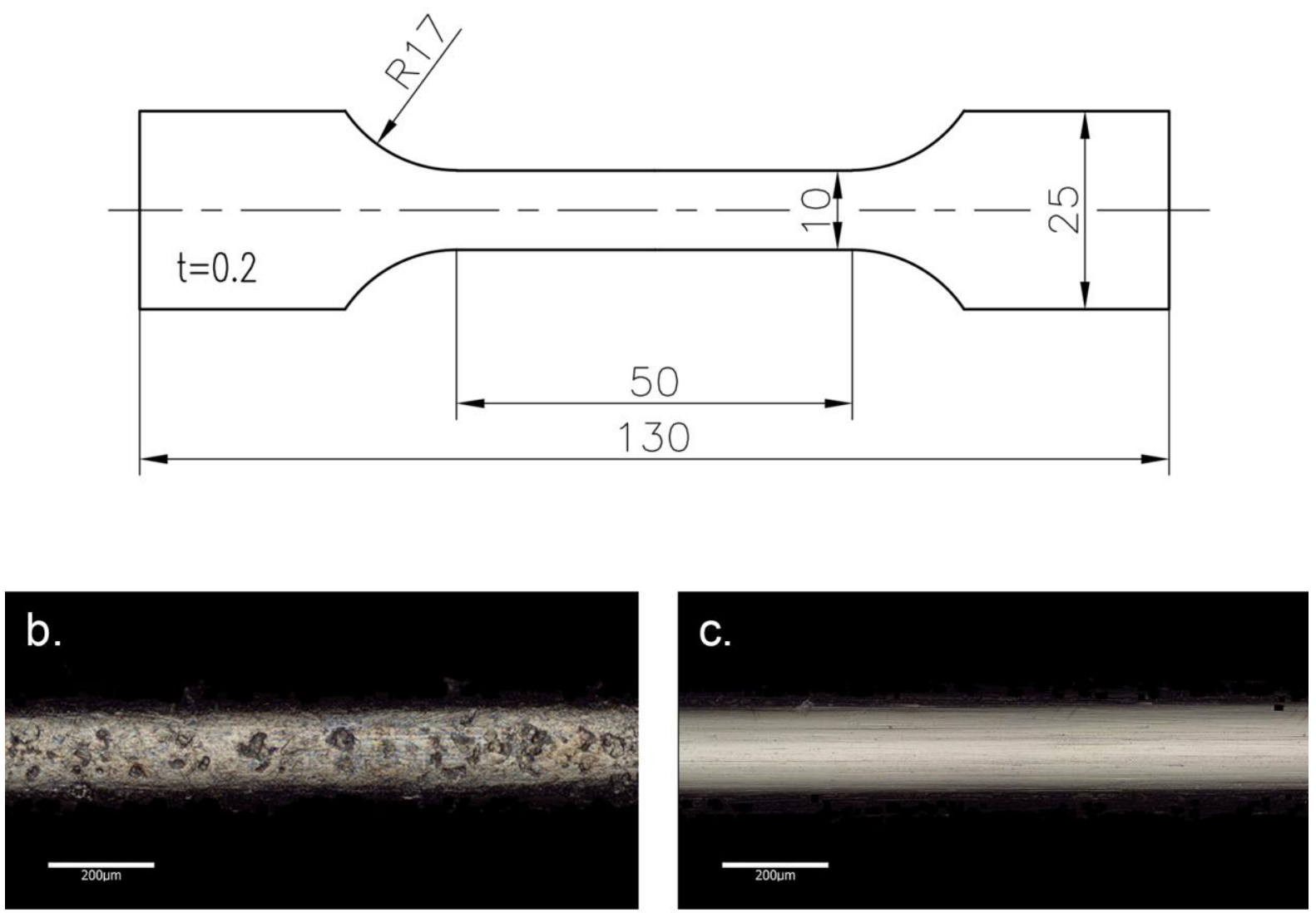

Fig. 1. Dimensions of evaluated sample in $\mathrm{mm}$ (a.) and a comparison of surface quality at the edge of the sample before (b.) and after (c.) manual polishing.
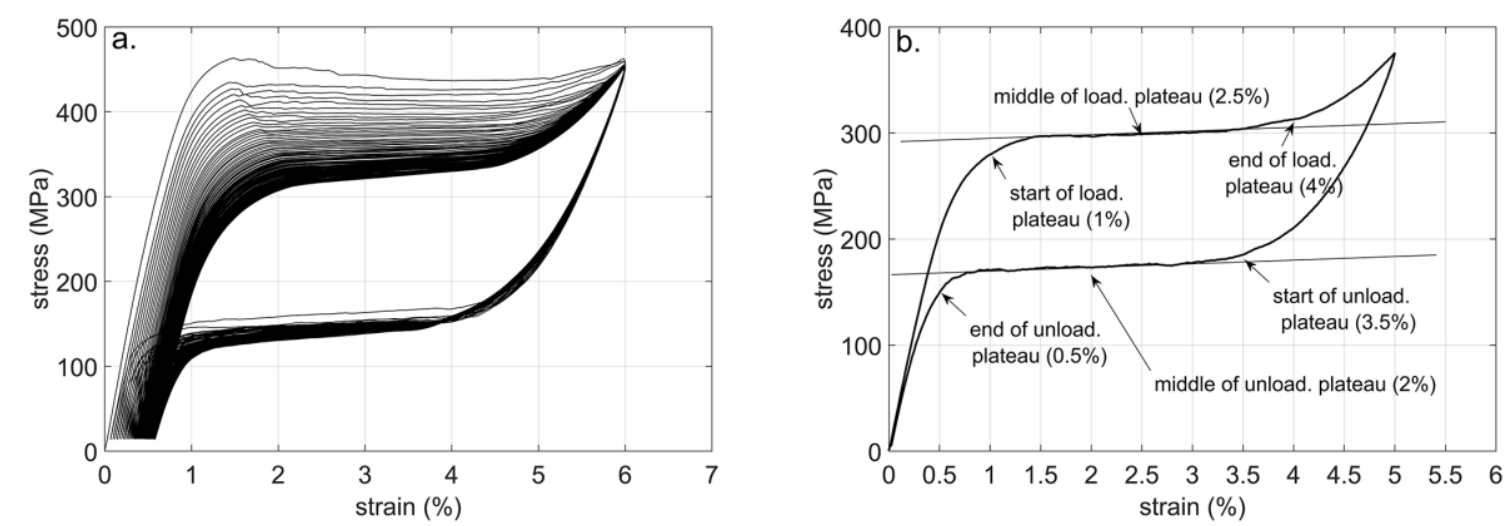

Fig 2. The stabilization of the superelastic response during training cycling (a.). The stabilized isothermal superelastic cycle with marked start, middle and end of the loading and the unloading transformation plateau (b.). 
This Author Accepted Manuscript (AAM) is published in:

Acta Materialia, vol. 150, 15 May 2018, p. 295-307

DOI: 10.1016/j.actamat.2018.03.032
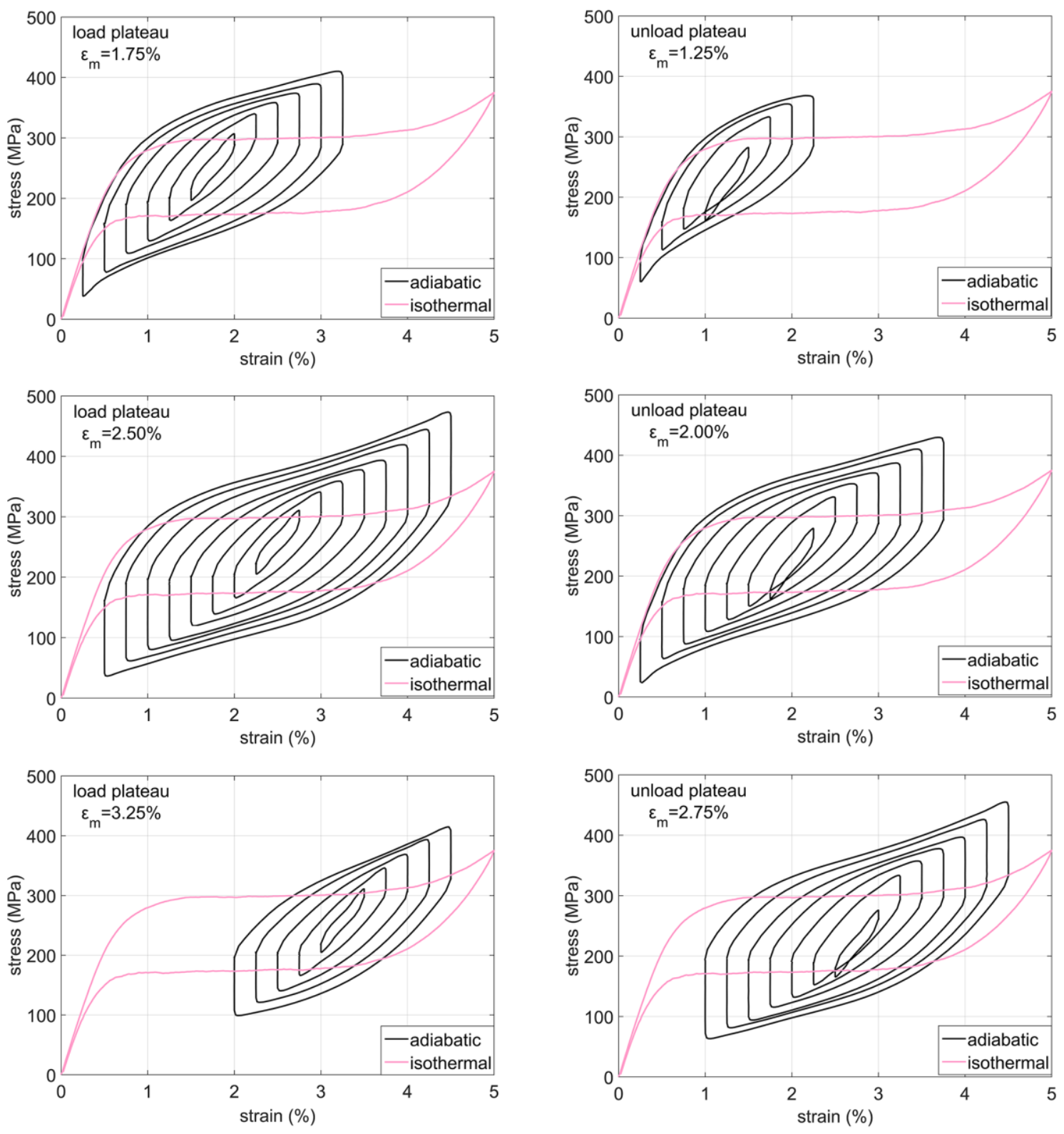

Fig. 3. Stress-strain characteristics for different strain amplitudes at different mean strains along the loading and unloading transformation plateau. 
This Author Accepted Manuscript (AAM) is published in:

Acta Materialia, vol. 150, 15 May 2018, p. 295-307

DOI: $10.1016 /$ j.actamat.2018.03.032
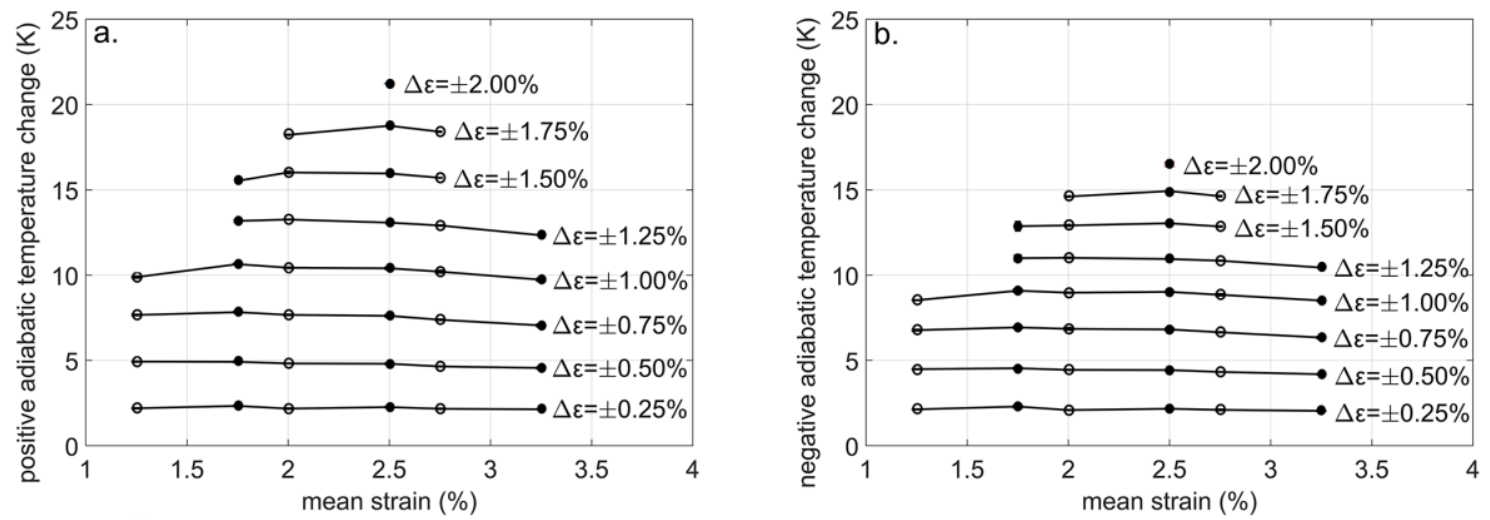

Fig. 4. Positive adiabatic temperature changes during loading (a.) and negative adiabatic temperature changes during unloading (b.) as a function of the mean strain for different strain amplitudes. Closed circles mark the adiabatic temperature changes measured at the loading plateau, while open circles at the unloading plateau. 
This Author Accepted Manuscript (AAM) is published in:

Acta Materialia, vol. 150, 15 May 2018, p. 295-307

DOI: 10.1016/j.actamat.2018.03.032

\section{Loading}
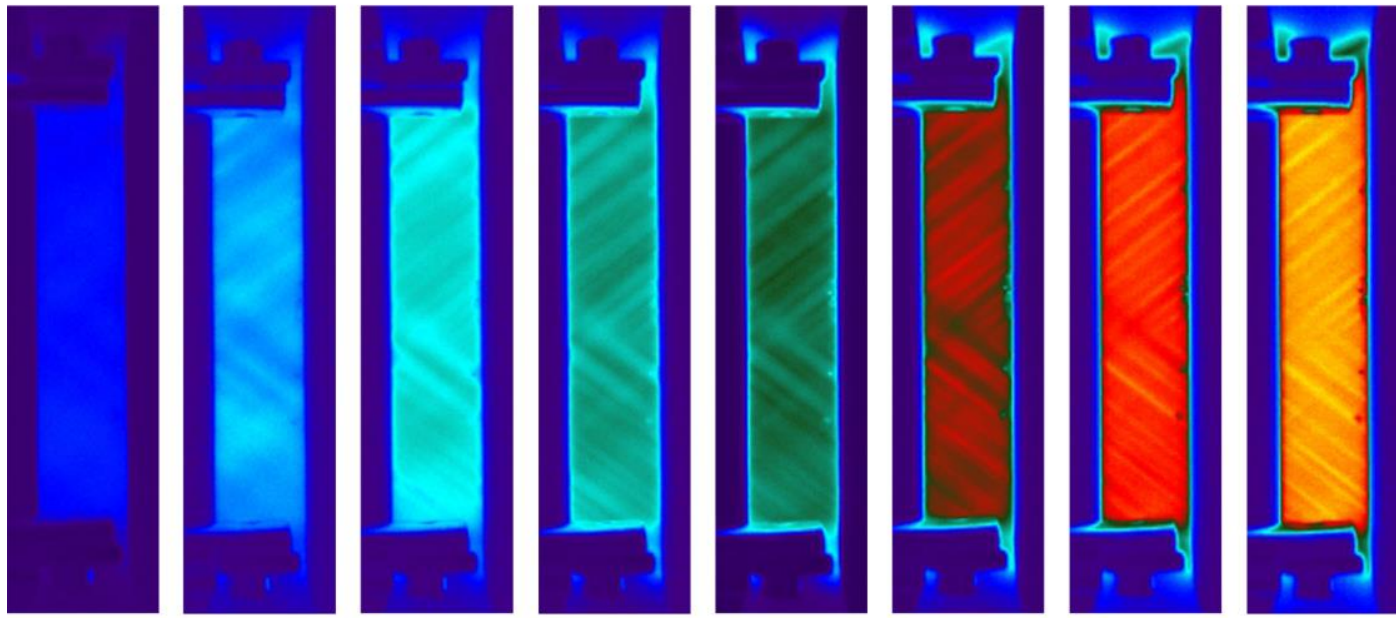

$\Delta \varepsilon= \pm 0.25 \%$

$\Delta \varepsilon= \pm 0.5 \%$

$\Delta \varepsilon= \pm 0.75 \%$

$\Delta \varepsilon= \pm 1 \%$

$\Delta \varepsilon= \pm 1.25 \% \quad \Delta \varepsilon= \pm 1.5 \%$

$\Delta \varepsilon= \pm 1.75 \%$

$\Delta \varepsilon= \pm 2 \%$

\begin{tabular}{|c|c|c|c|c|c|c|c|c|c|c|c|c|c|c|c|}
\hline$N$ & $N$ & के & $\stackrel{N}{\infty}$ & $\omega$ & $\omega$ & $\omega$ & $\omega$ & $\omega$ & 응 & A & A & के & कि & 잉 & N \\
\hline 0 & I & $\mathcal{G}$ & A & A & A & A & A & A & A & A & A & A & A & i & 0 \\
\hline
\end{tabular}

\section{Unloading}

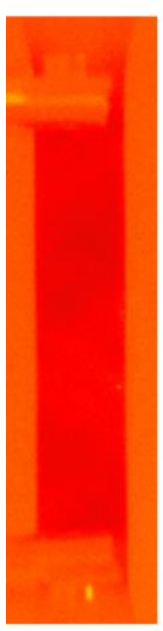

$\Delta \varepsilon= \pm 0.25 \%$

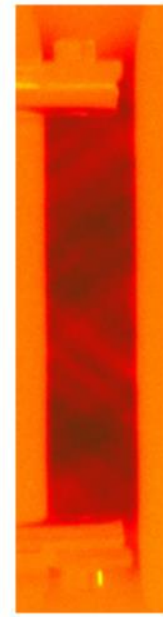

$\Delta \varepsilon= \pm 0.5 \%$

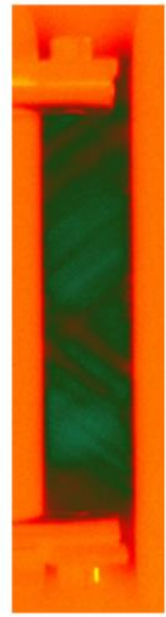

$\Delta \varepsilon= \pm 0.75 \%$

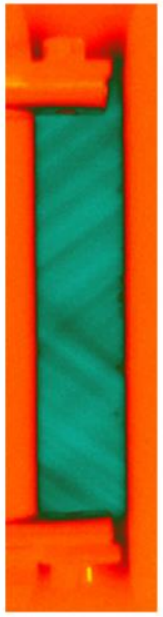

$\Delta \varepsilon= \pm 1 \%$

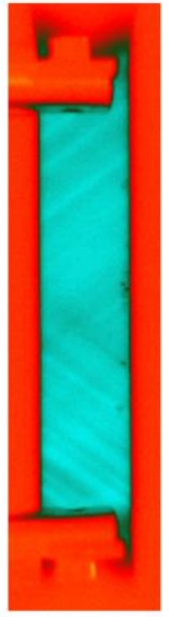

$\Delta \varepsilon= \pm 1.25 \%$

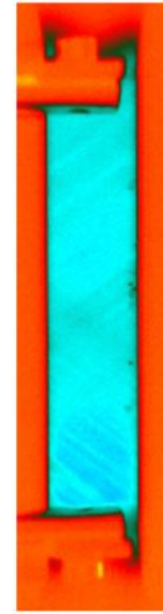

$\Delta \varepsilon= \pm 1.5 \%$

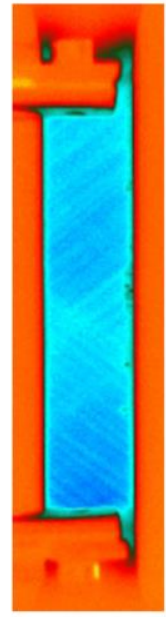

$\Delta \varepsilon= \pm 1.75 \%$

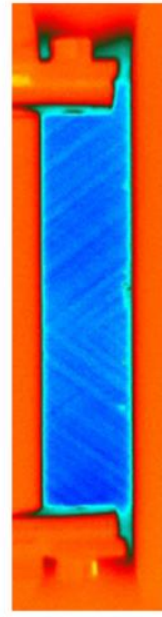

$\Delta \varepsilon= \pm 2 \%$

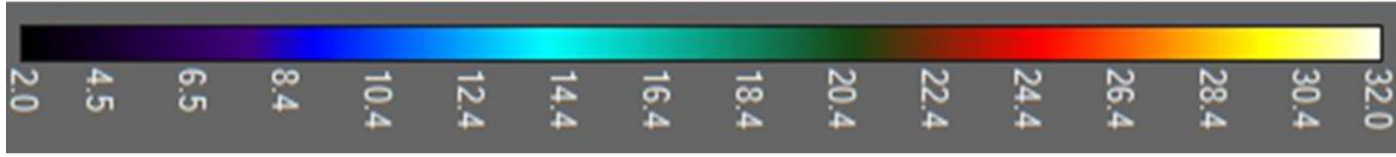

Fig. 5. Temperature distribution (in ${ }^{\circ} \mathrm{C}$ ) over the sample immediately after the loading and unloading with strain amplitudes from $0.25 \%$ to $2.00 \%$ at mean strain of $2.50 \%$ at the loading plateau. 
This Author Accepted Manuscript (AAM) is published in:

Acta Materialia, vol. 150, 15 May 2018, p. 295-307

DOI: 10.1016/j.actamat.2018.03.032

\section{Loading}

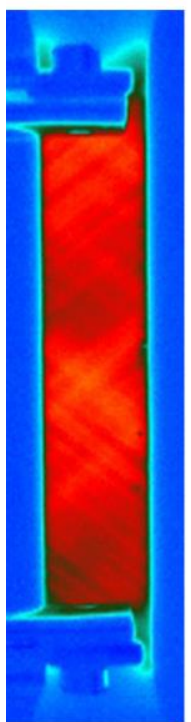

$\varepsilon_{\mathrm{m}}=1.25 \%$

$\varepsilon_{\mathrm{m}}=1.75 \%$

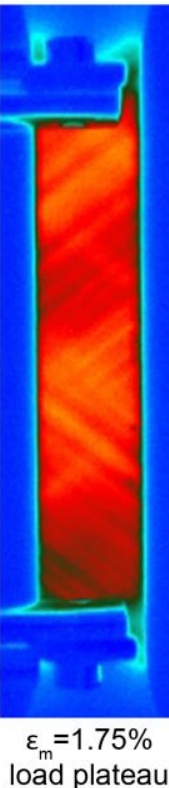

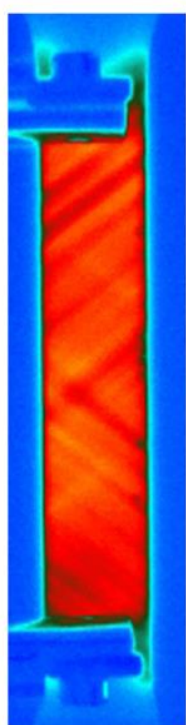

$\varepsilon_{\mathrm{m}}=2 \%$

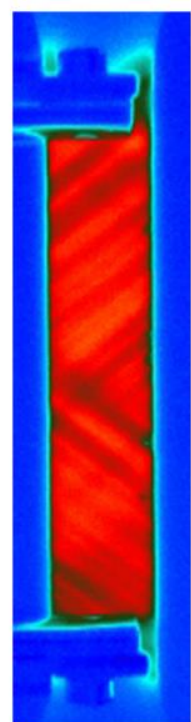

$\varepsilon_{\mathrm{m}}=2.5 \%$

unload plateau load plateau unload plateau load plateau

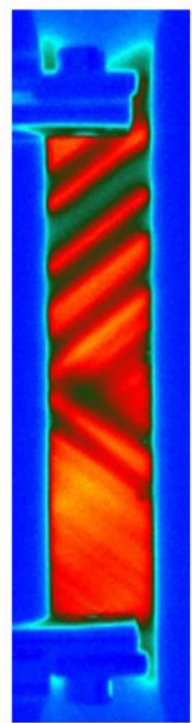

$\varepsilon_{\mathrm{m}}=2.75 \%$

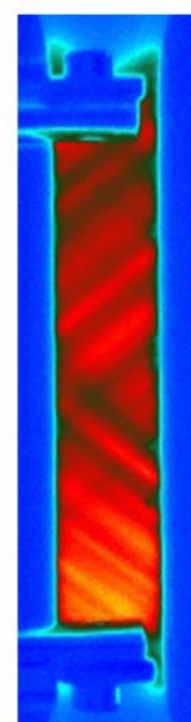

$\varepsilon_{\mathrm{m}}=3.25 \%$

unload plateau

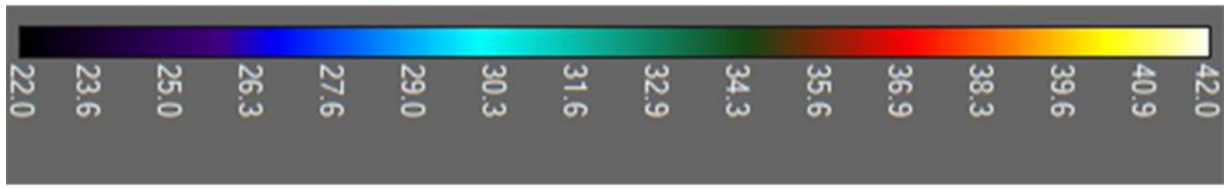

\section{Unloading}

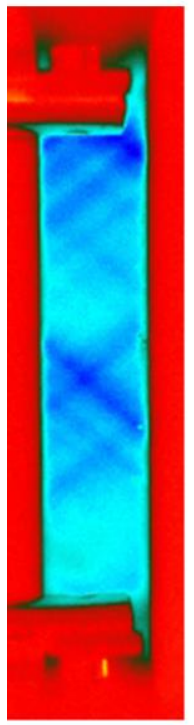

$\varepsilon=1.25 \%$

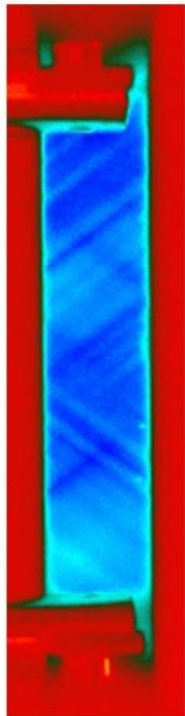

$\varepsilon_{\mathrm{m}}=1.75 \%$

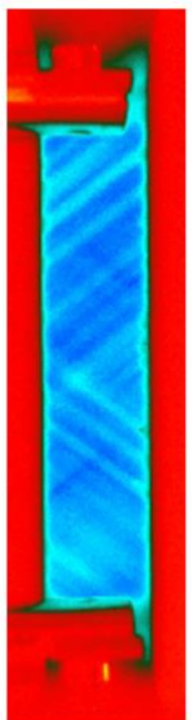

$\varepsilon_{m}=2 \%$

unload plateau load plateau unload plateau load plateau unload plateau load plateau

unload plateau load plateau unload plateau load plateau unload plateau load plateau

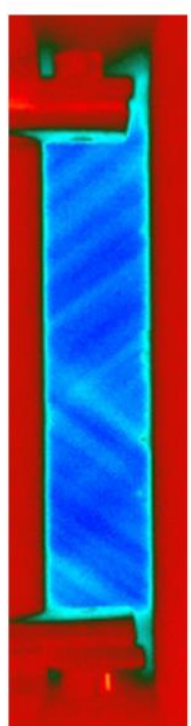

$\varepsilon_{m}=2.5 \%$

unload plateau load plateau unload plateau load plateau unload plateau load plateau

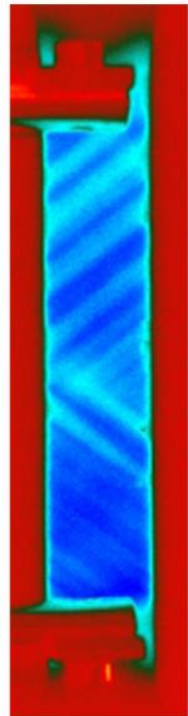

$\varepsilon=2.75 \%$

unload plateau load plateau unload plateau load plateau unload plateau load plateau

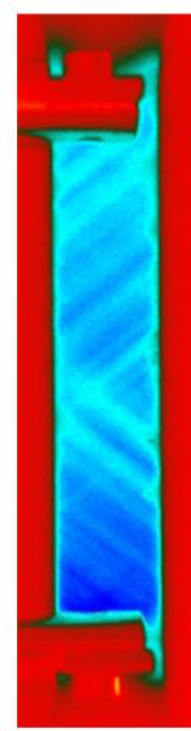

$\varepsilon=3.25 \%$

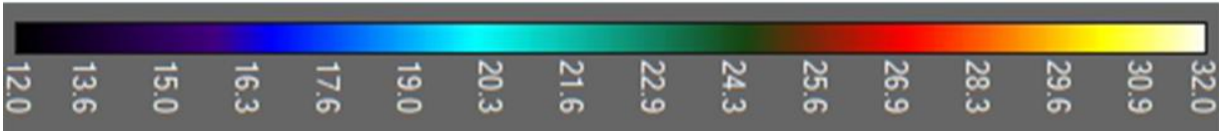

Fig. 6. Temperature distribution (in ${ }^{\circ} \mathrm{C}$ ) over the sample immediately after loading and unloading with a strain amplitude of $1.00 \%$ at mean strains of $1.75 \%, 2.50 \%, 3.25 \%$ at the loading plateau and $1.25 \%, 2.00 \%, 2.75 \%$ at the unloading plateau,

respectively. 
This Author Accepted Manuscript (AAM) is published in:

Acta Materialia, vol. 150, 15 May 2018, p. 295-307

DOI: $10.1016 /$ j.actamat.2018.03.032
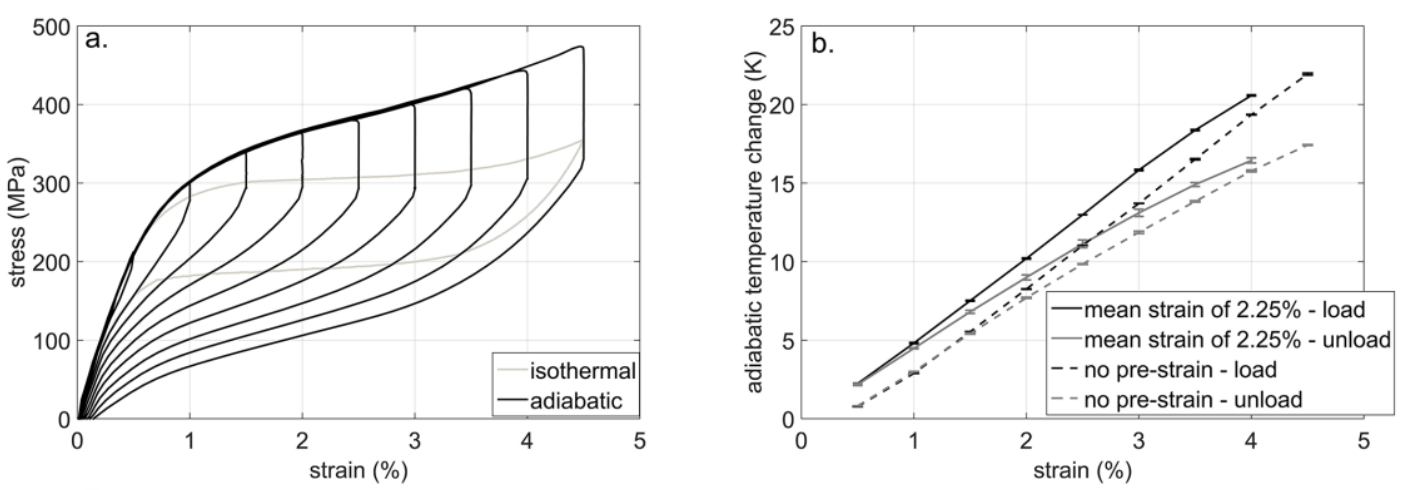

Fig. 7. Stress-strain characteristics at no pre-strain conditions (a.). A comparison of adiabatic temperature changes as a function of total strain at no pre-strain conditions and at a mean strain of $2.25 \%$ at the loading plateau (b.).

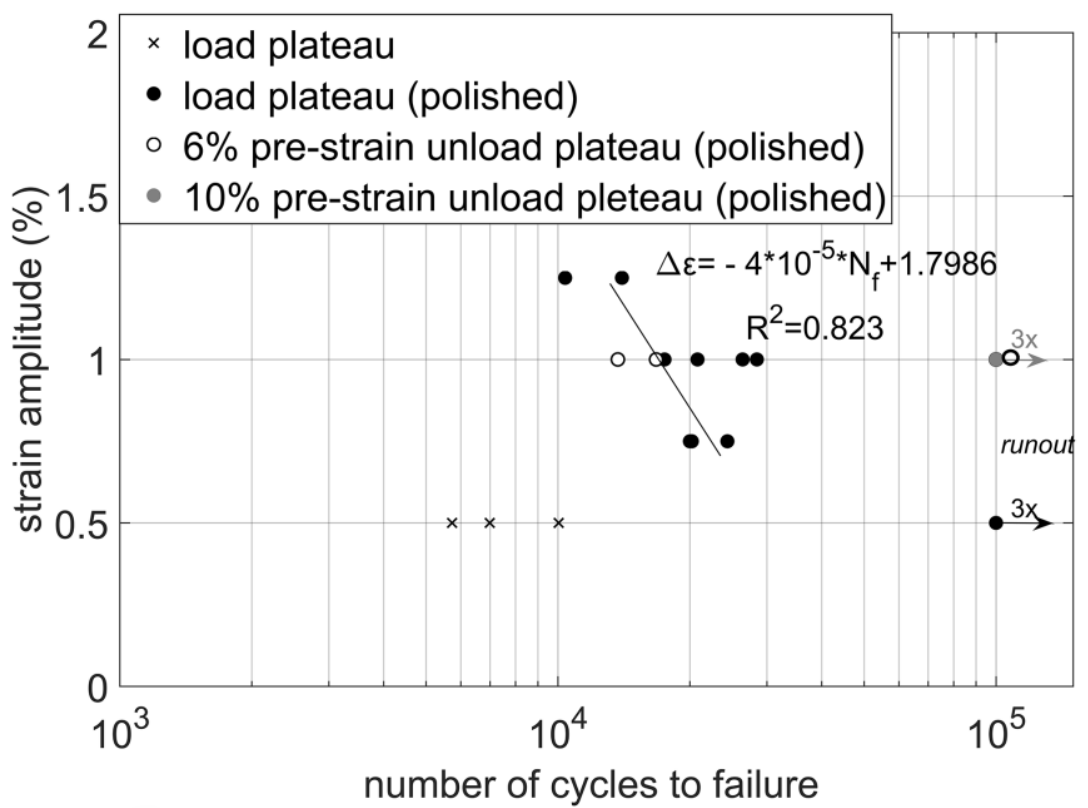

Fig. 8. Strain-life fatigue data for all evaluated samples. 
This Author Accepted Manuscript (AAM) is published in:

Acta Materialia, vol. 150, 15 May 2018, p. 295-307

DOI: $10.1016 /$ j.actamat.2018.03.032
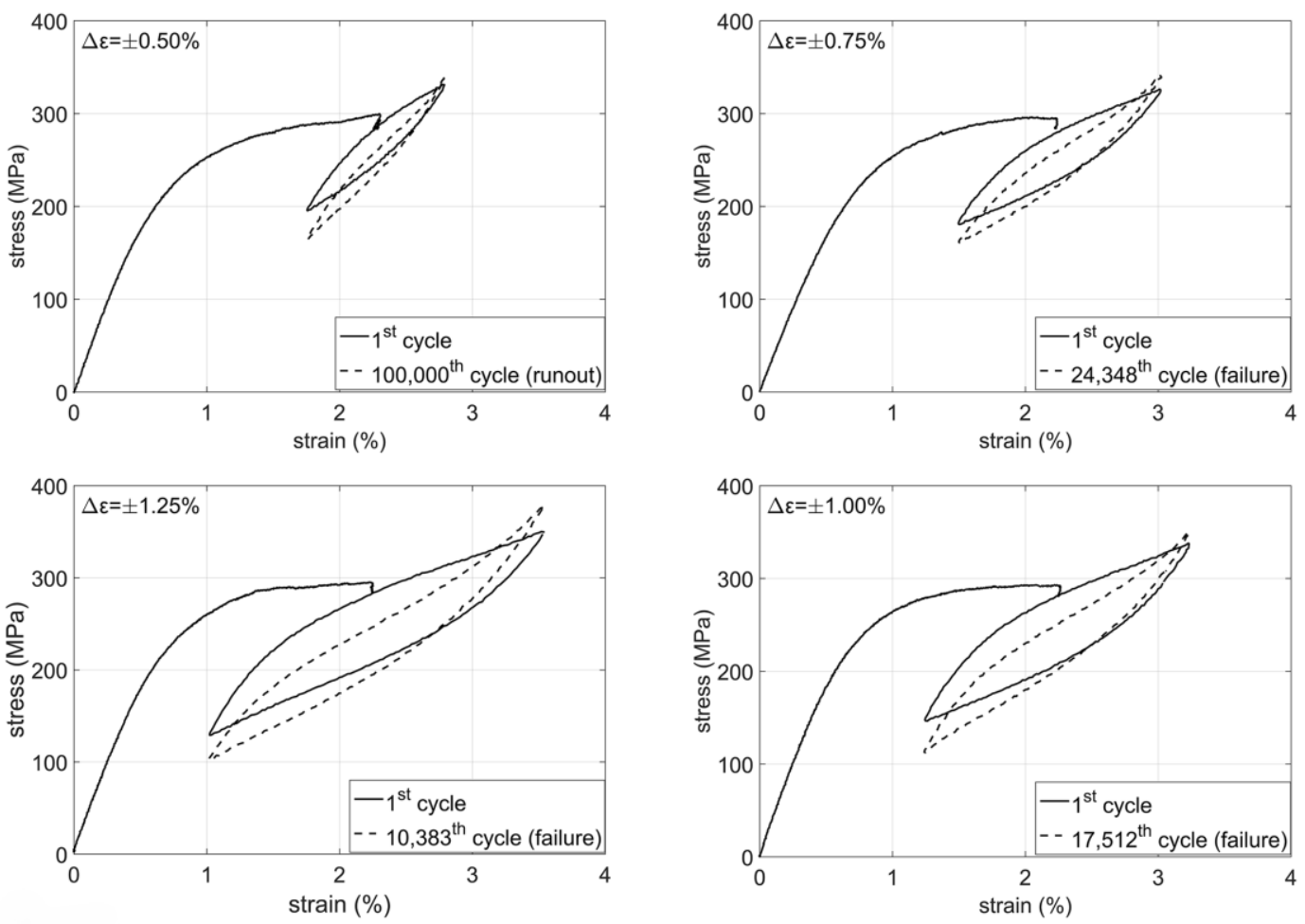

Fig. 9. Stress-strain characteristics of the first and the last cycles during fatigue testing at different strain amplitudes at the mean strain of $2.25 \%$ at the loading plateau.

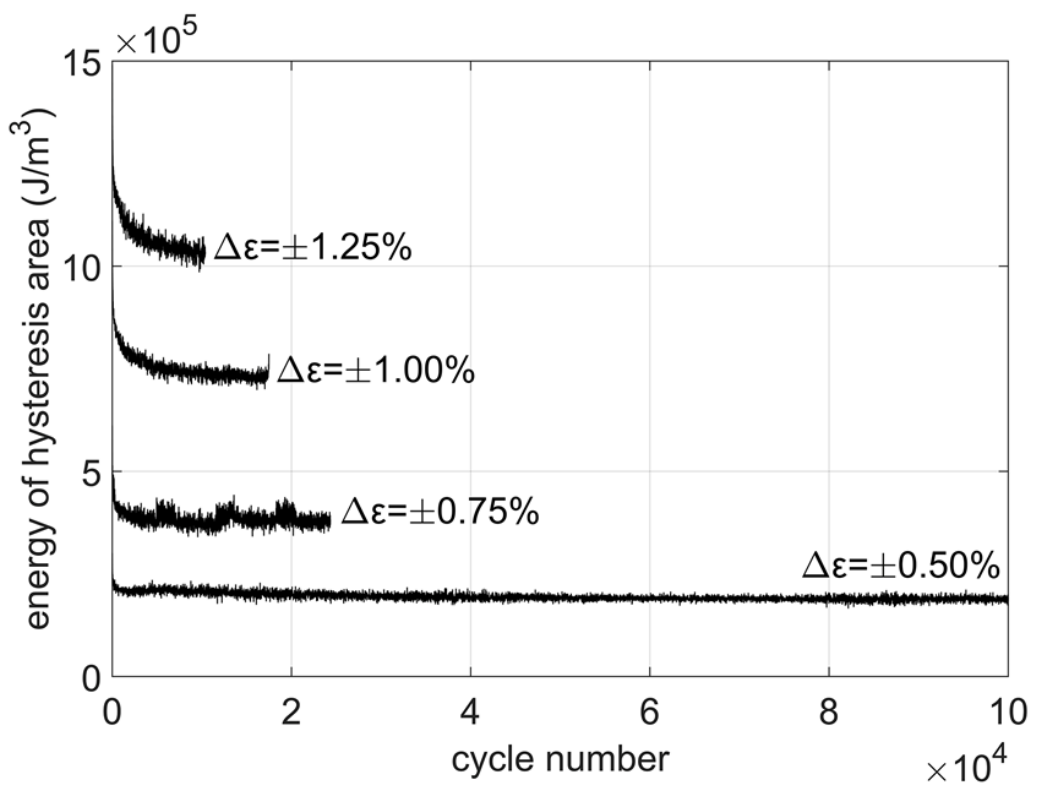

Fig. 10. The energy of hysteresis area during fatigue testing as function of cycle number for different strain amplitudes (at the means strain of $2.25 \%$ at the loading plateau). 
This Author Accepted Manuscript (AAM) is published in:

Acta Materialia, vol. 150, 15 May 2018, p. 295-307

DOI: 10.1016/j.actamat.2018.03.032
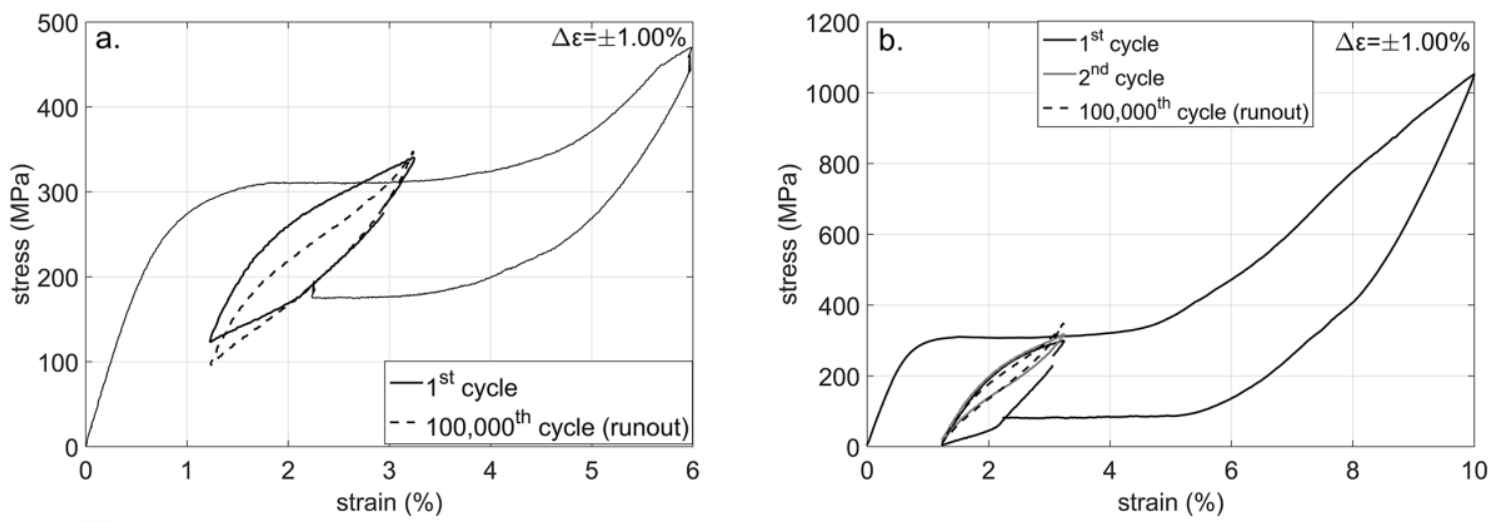

Fig. 11. Stress-strain characteristics of the first (two) and the last cycle during fatigue testing at the strain amplitude of $1 \%$ and the mean strain of $2.25 \%$ at the unloading plateau after the initial pre-strain up to $6 \%$ (a.) and 10\% (b.).

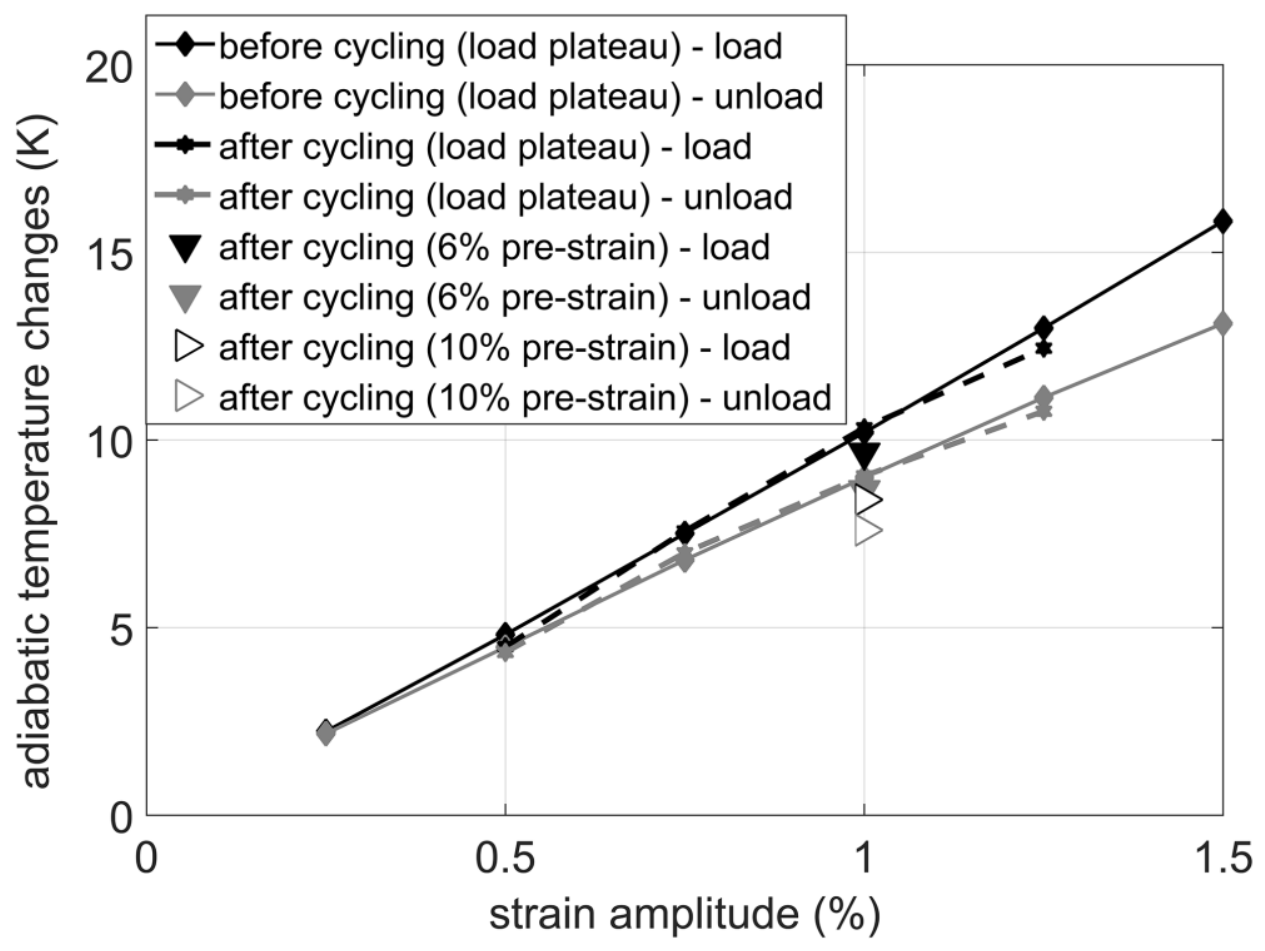

Fig. 12. Comparison of adiabatic temperature changes before and after fatigue cycling. 